\title{
Microwave Catalytic Degradation of Antibiotic Molecules by 2D Sheets of Spinel Nickel Ferrite
}

\author{
Sandhya Mishra1, Prashant Kumar ${ }^{2,3 *}$ and Sujoy Kumar Samanta ${ }^{1^{*}}$ \\ ${ }^{1}$ Department of Chemical and Biochemical Engineering, Indian Institute of Technology Patna, Bihta, Patna, Bihar \\ 801106, India. \\ ${ }^{2}$ Department of Physics, Indian Institute of Technology Patna, Bihta, Patna, Bihar 801106, India. \\ ${ }^{3}$ Birck Nanotechnology Centre, Purdue University, West Lafayette, Indiana 47907, United States.
}

*Dr. Prashant Kumar: Phone, +91-612 302 8141, +91-9102830953, E-mail: prashantkumar@iitp.ac.in, magmemory@gmail.com

*Dr. Sujoy Kumar Samanta: Phone: +91-612 302 8173, +91-9835355046, E-mail: sksamanta@iitp.ac.in, krsanju07@gmail.com 
a
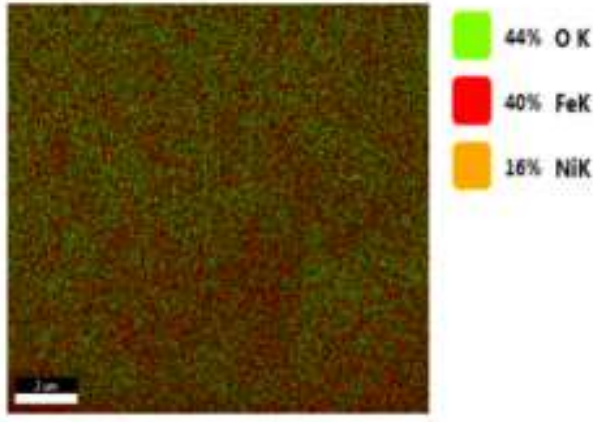

C

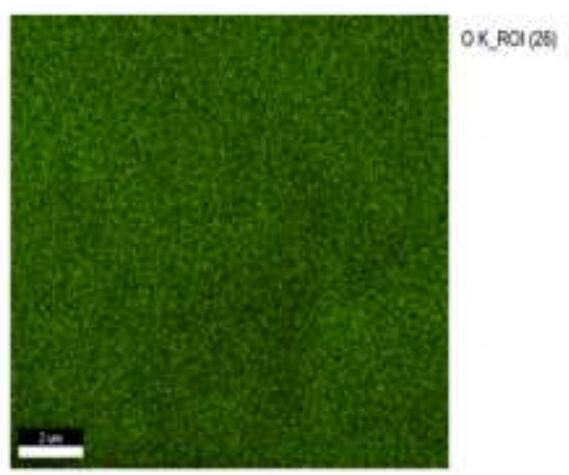

b
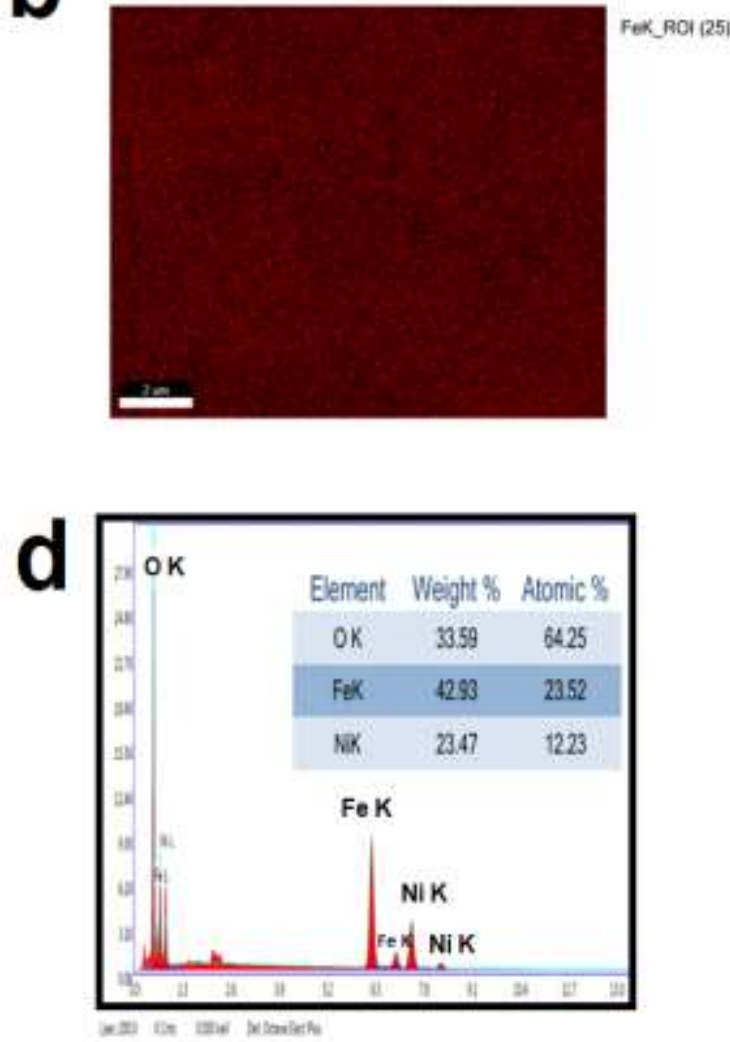

Figure S1. The elemental mapping and SEM-EDS of the SNFO catalyst. 

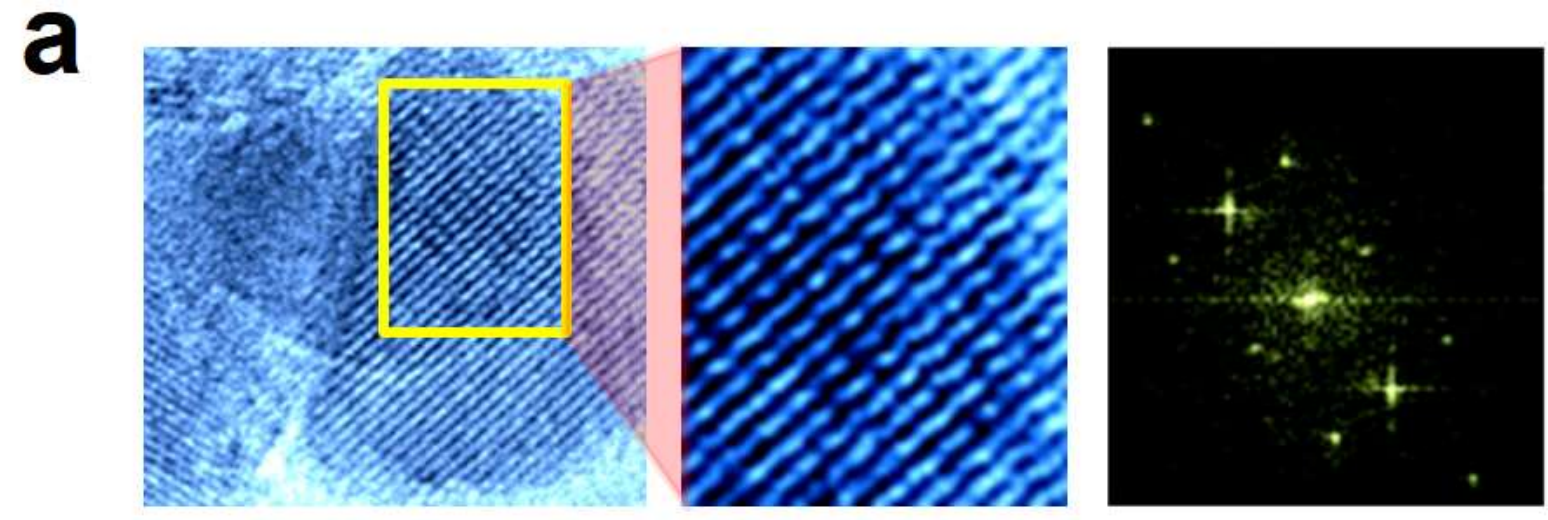

b
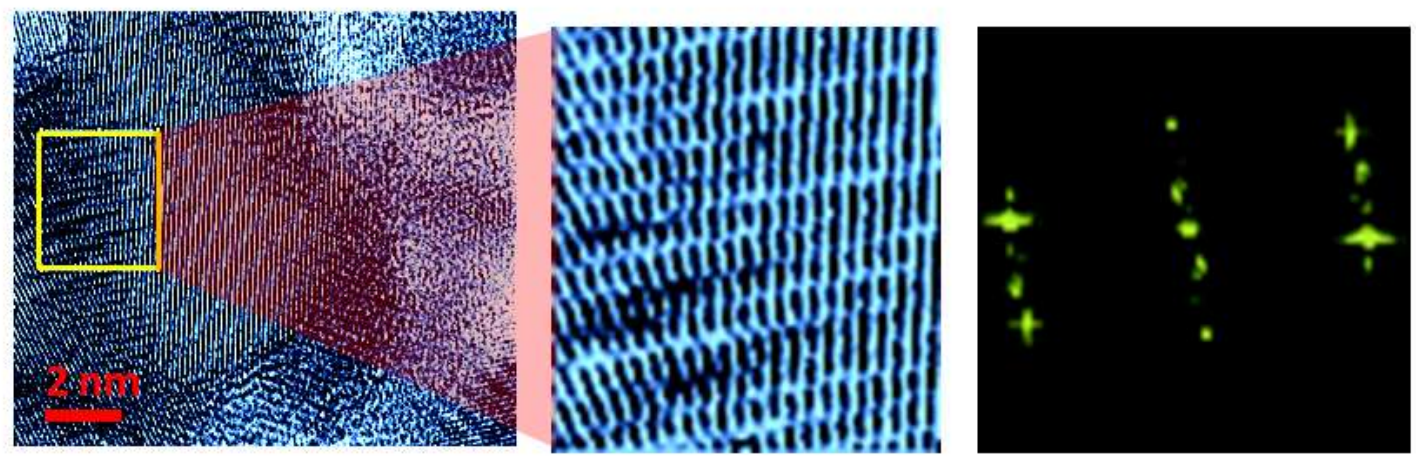

Figure S2. HRTEM images and FFT of SNFO catalyst. 
a

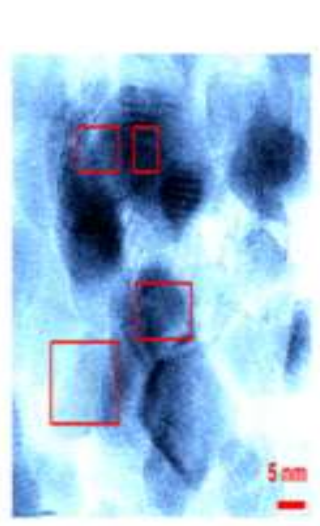

b
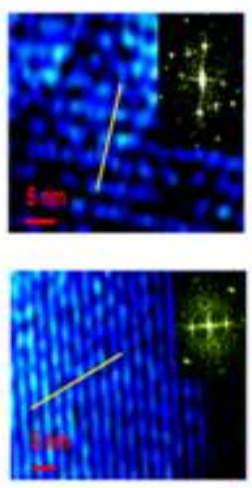

C
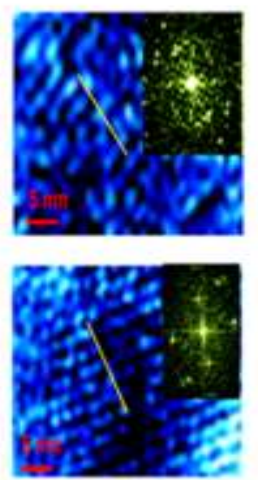

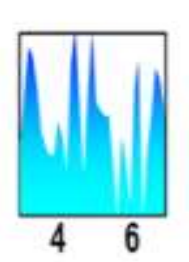

Dist. (nm) Dist. (nm)

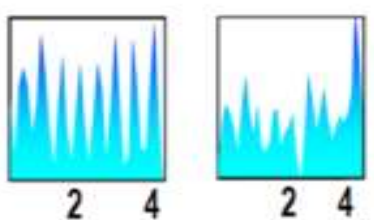

Dist. (nm) Dist. (nm)

Figure S3. HRTEM images, FFT and the line profiles of the SNFO sheets. 


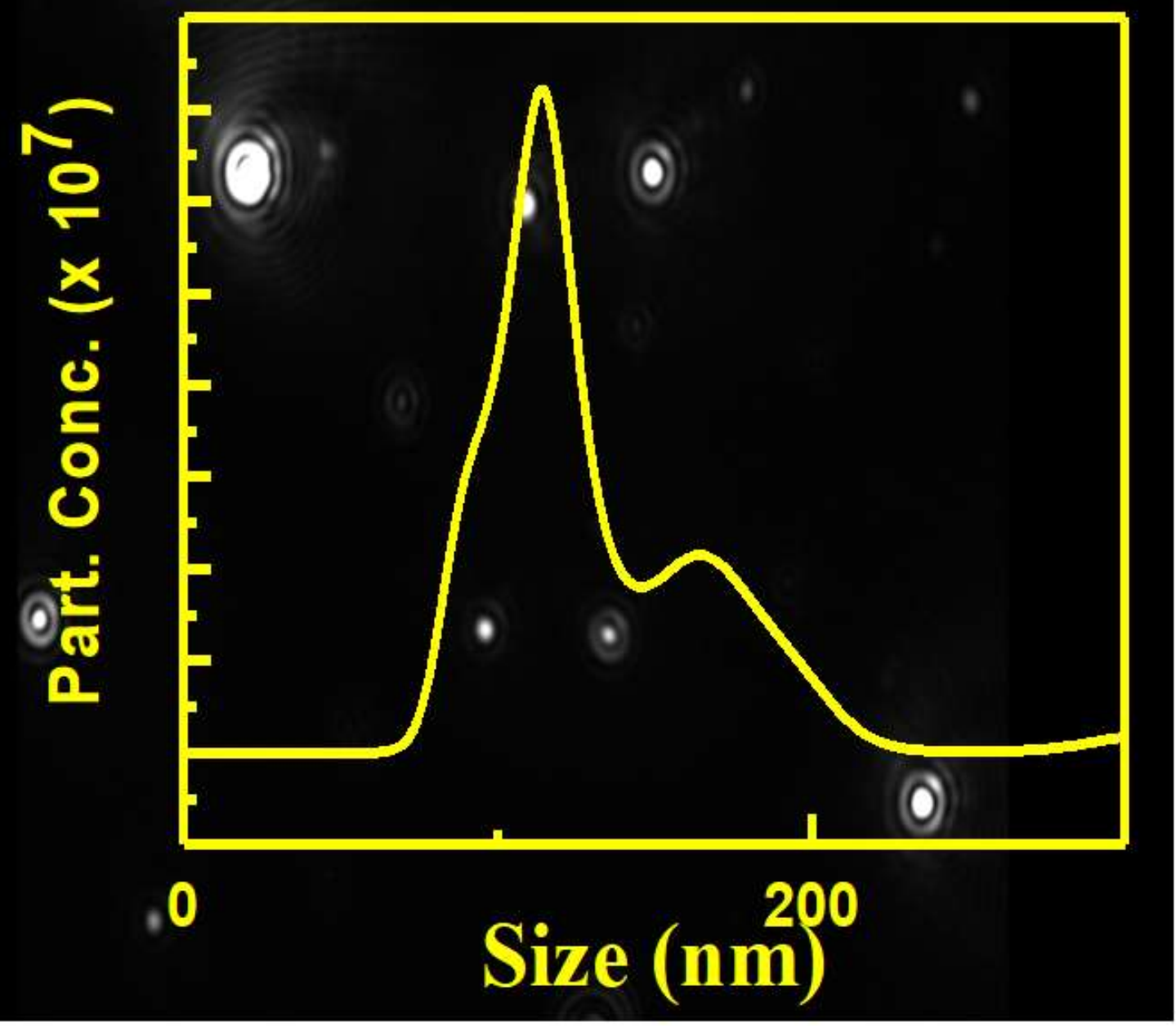

Figure S4. The hydrodynamic particle size distribution of the magnetic SNFO sheets. 

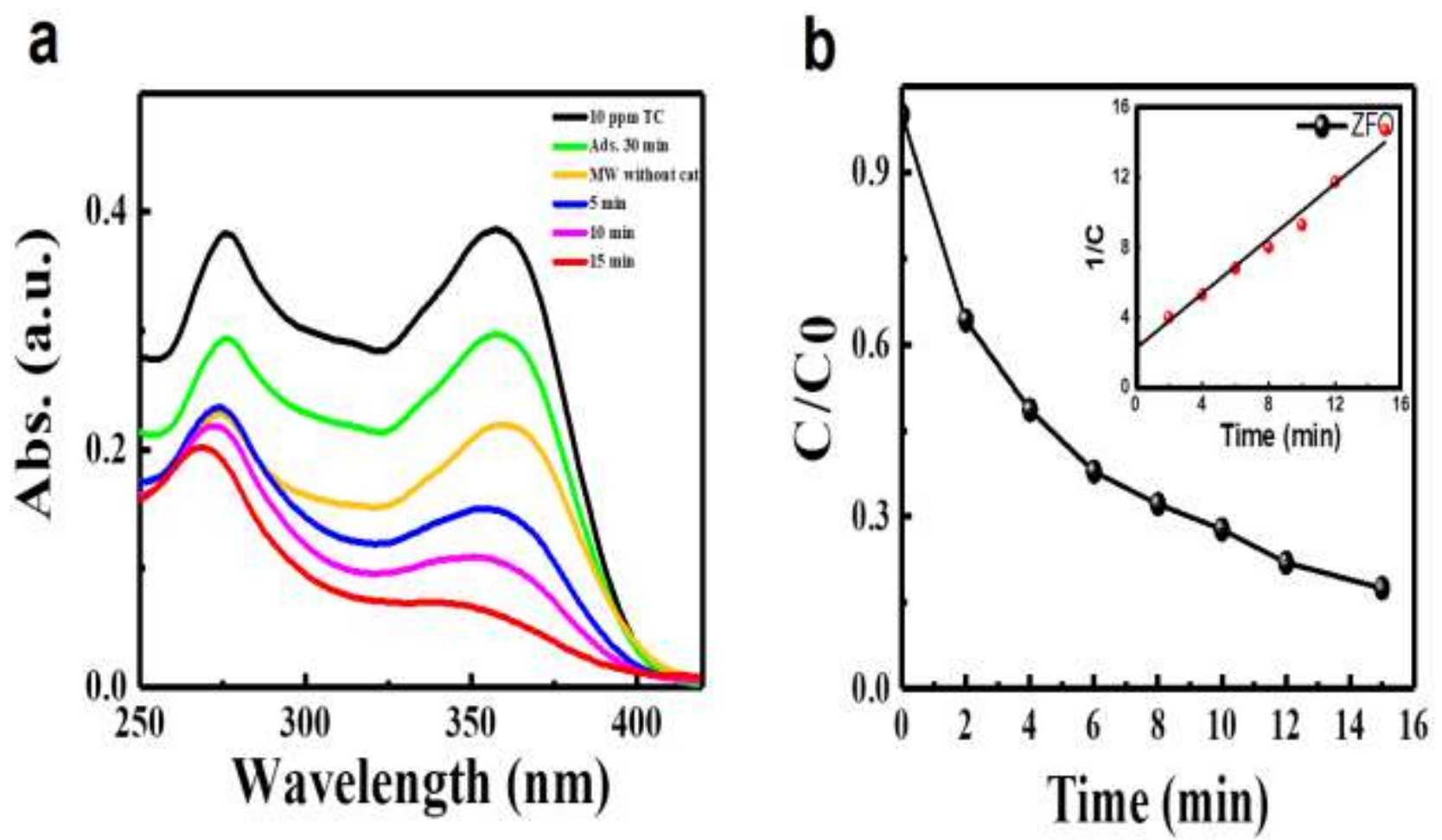

Figure S5 (a) UV-Vis spectra recorded after the degradation with time; (b) the kinetics plot for the TCH antibiotic degradation with SZFO under the MW irradiation. 


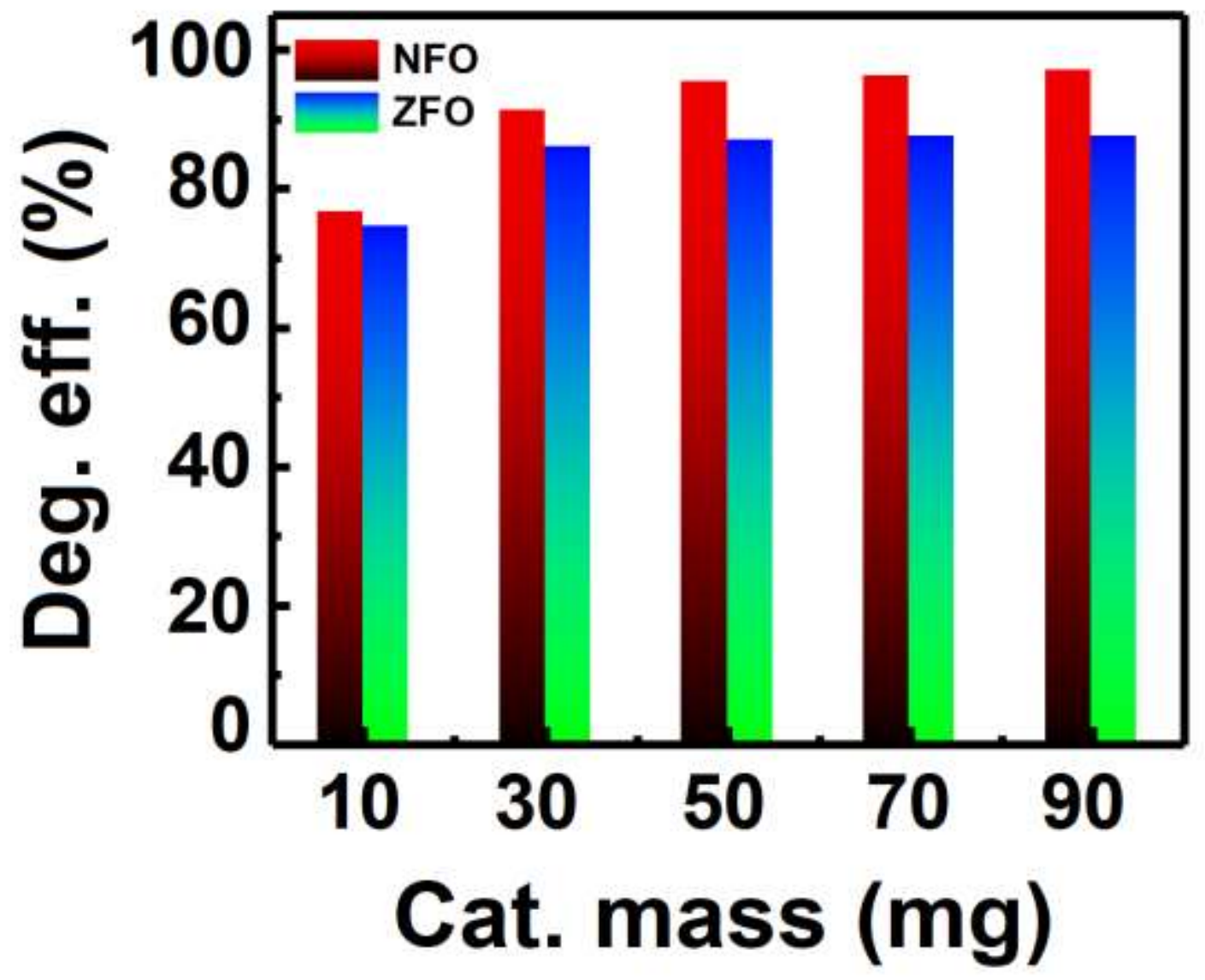

Figure S6. The effect of the catalyst mass on the TCH antibiotic degradation using SNFO and SZFO catalysts. 

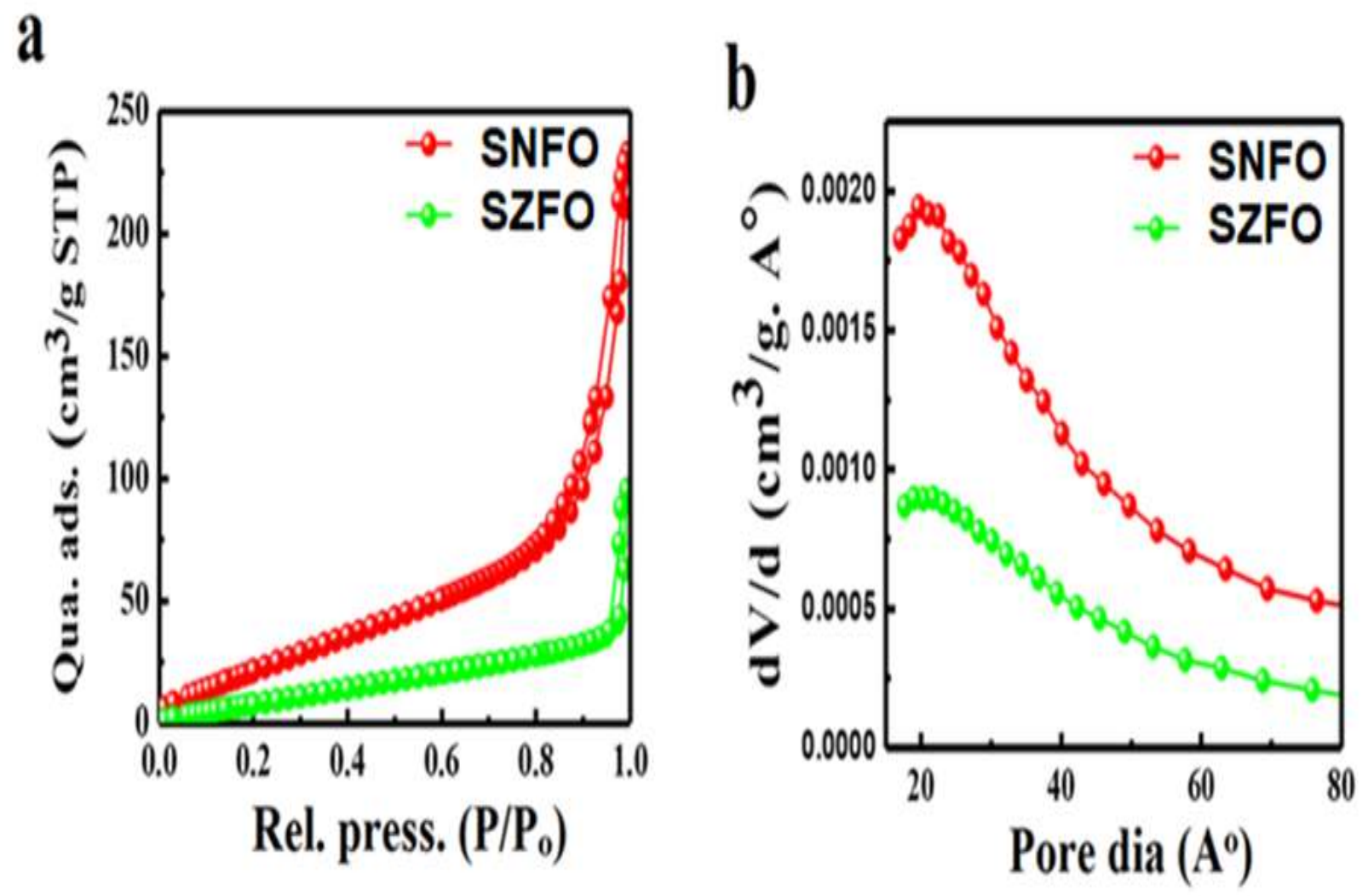

Figure S7 (a) $\mathrm{N}_{2}$ adsorption-desorption isotherm; (b) pore volume vs pore diameter plots for SNFO and SZFO catalysts. 


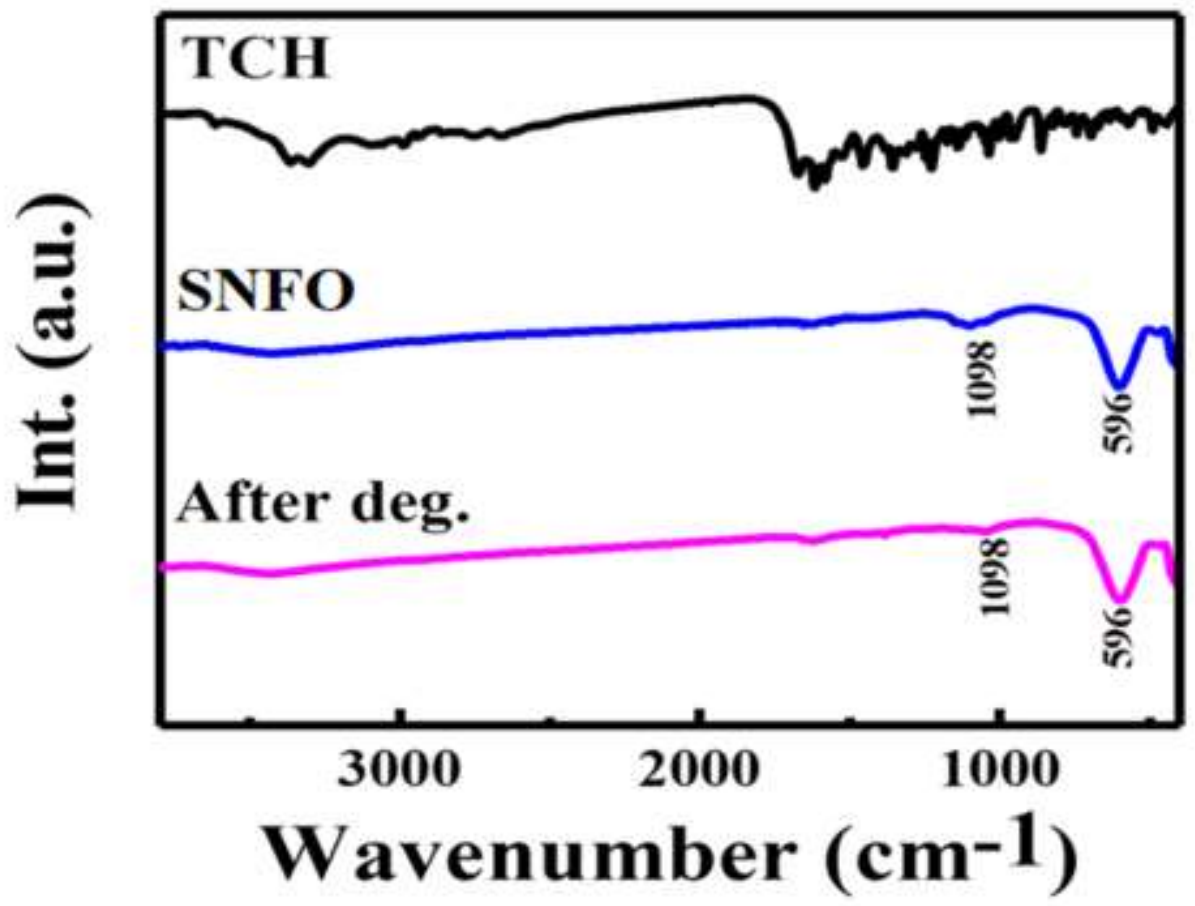

Figure S8. FTIR spectra of the TCH antibiotic molecule anchored on the SNFO catalyst before and after the degradation. 


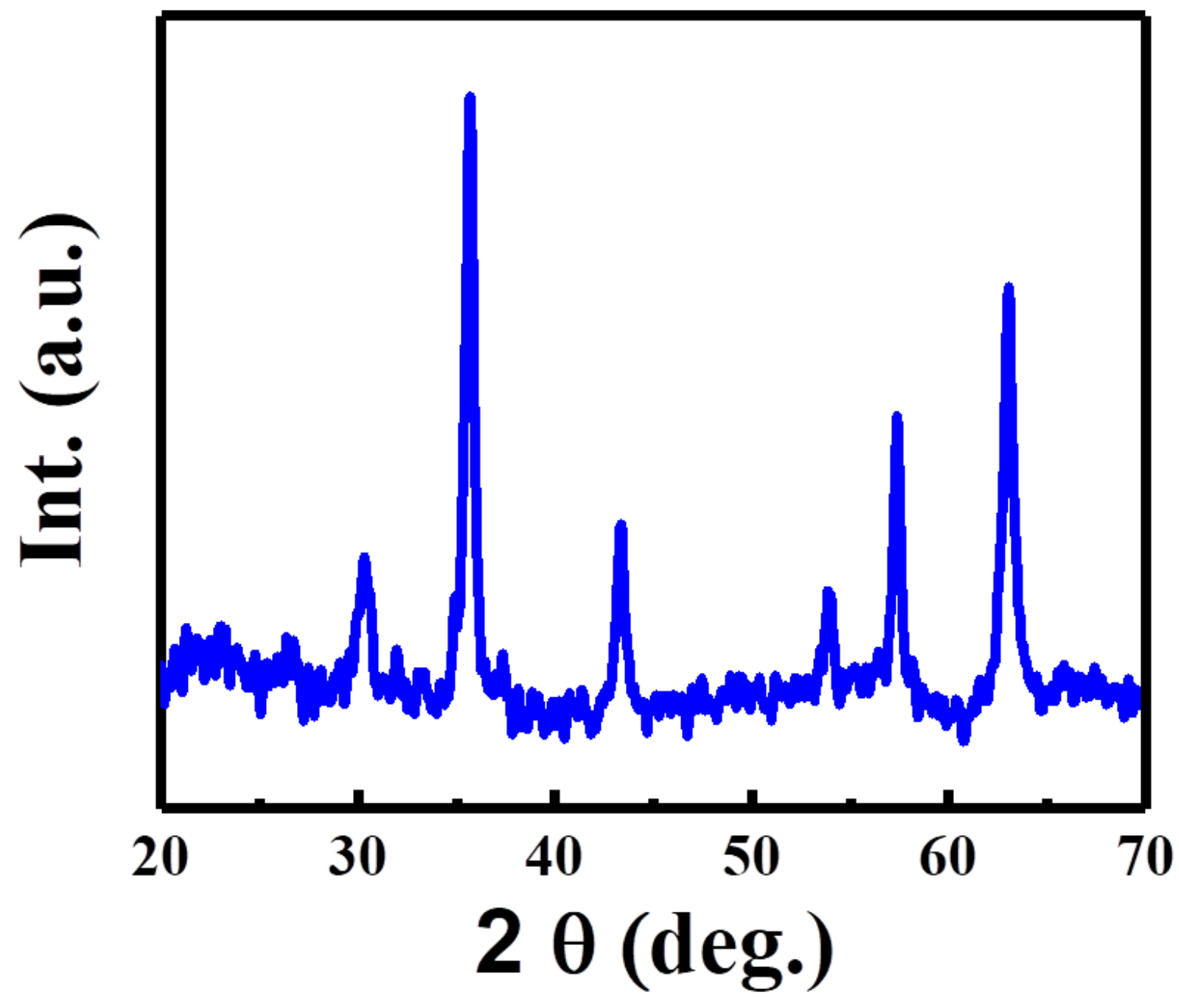

Figure S9. XRD pattern of SNFO after the MW treatment. 

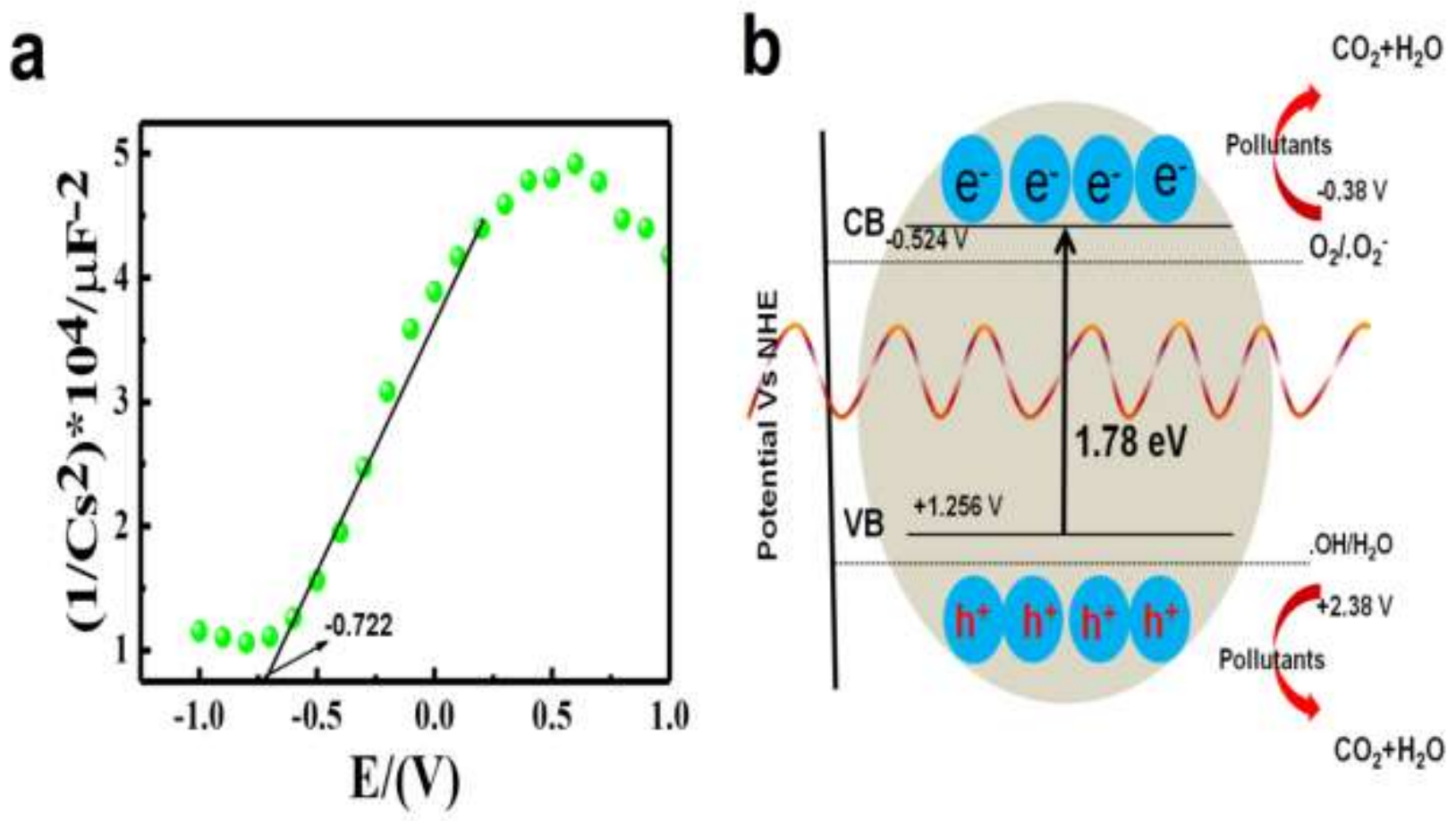

Figure S10 (a) The Mott-Schottky plots for SNFO; (b) the mechanism of generations of the electrons and holes under the MW irradiation for SNFO. 
Table S1. The comparisons of the degradation efficiency and TOC removal of other methods reported in the literature with those of the present method for the degradataion of the TCH antibiotic.

\begin{tabular}{|c|c|c|c|c|c|c|c|c|}
\hline Catalyst & Method & pH & $\begin{array}{l}\text { Power } \\
(\mathrm{W})\end{array}$ & $\begin{array}{c}\text { Initial } \\
\text { Concentrat } \\
\text { ion }\end{array}$ & $\begin{array}{l}\text { Time } \\
(\min )\end{array}$ & $\begin{array}{c}\text { Degradation } \\
\text { efficiency } \\
(\%)\end{array}$ & $\begin{array}{l}\text { TOC } \\
(\%)\end{array}$ & References \\
\hline $\mathrm{Ti}_{4} \mathrm{O}_{7}$ & Ozonation & 7 & $\mathrm{NG}^{*}$ & $5 \mathrm{mg} / \mathrm{L}$ & 80 & 77.1 & 9.1 & {$[64]$} \\
\hline $\mathrm{BiFeO}_{3}$ & Photo-Fenton & 3 & 120 & $10 \mathrm{mg} / \mathrm{L}$ & 120 & 40 & 21 & {$[65]$} \\
\hline $\mathrm{Fe}^{+2} / \mathrm{H}_{2} \mathrm{O}_{2}$ & Ultrasound & 6 & 100 & $100 \mathrm{mg} / \mathrm{L}$ & 60 & 85.1 & 18.7 & [66] \\
\hline $\mathrm{TiO}_{2}$ & Photocatalysis & 6 & 120 & $40 \mathrm{mg} / \mathrm{L}$ & 120 & 75 & 15 & [67] \\
\hline $\mathrm{NiFe}_{2} \mathrm{O}_{4}$ & Photocatalysis & $N^{*}$ & 150 & $10 \mathrm{mg} / \mathrm{L}$ & 90 & 47.43 & $\mathrm{NG}^{*}$ & [68] \\
\hline $\begin{array}{c}\text { Boron- } \\
\text { doped } \\
\text { diamond( } \\
\text { BDD)/car } \\
\text { bon-felt } \\
\text { electrode, } \\
\mathrm{Fe}^{3+}, \mathrm{Fe}^{2+}\end{array}$ & $\begin{array}{l}\text { Electro- } \\
\text { Fenton }\end{array}$ & 7 & 18 & $100 \mathrm{mg} / \mathrm{L}$ & 120 & 87.5 & 15 & [69] \\
\hline SNFO & $\begin{array}{l}\text { MW assisted } \\
\text { method }\end{array}$ & 6 & 700 & $10 \mathrm{mg} / \mathrm{L}$ & 15 & 90 & 40 & $\begin{array}{l}\text { Present } \\
\text { work }\end{array}$ \\
\hline
\end{tabular}

* $\mathrm{NG}=$ Not Given 


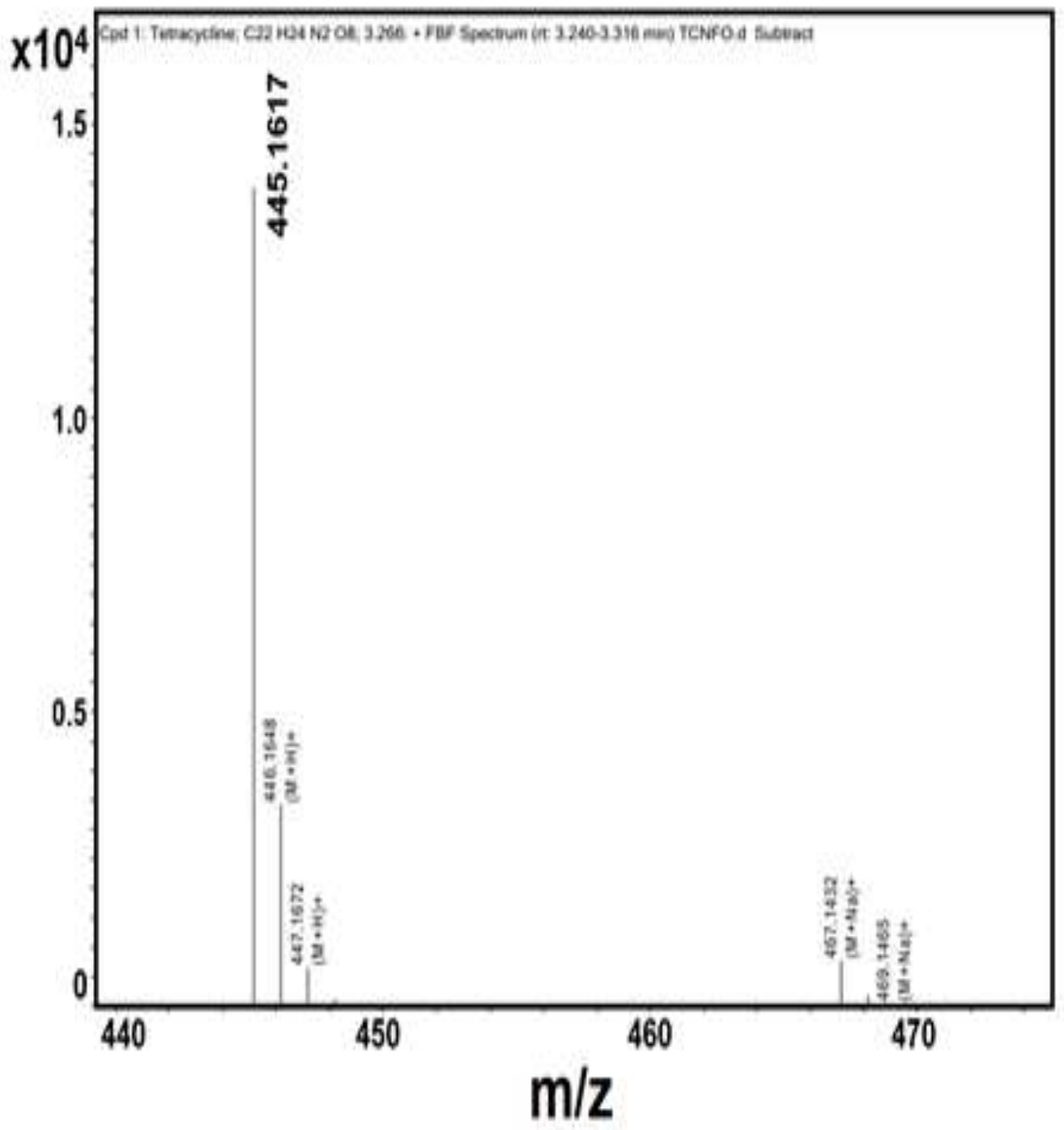

Figure S11 (a) 


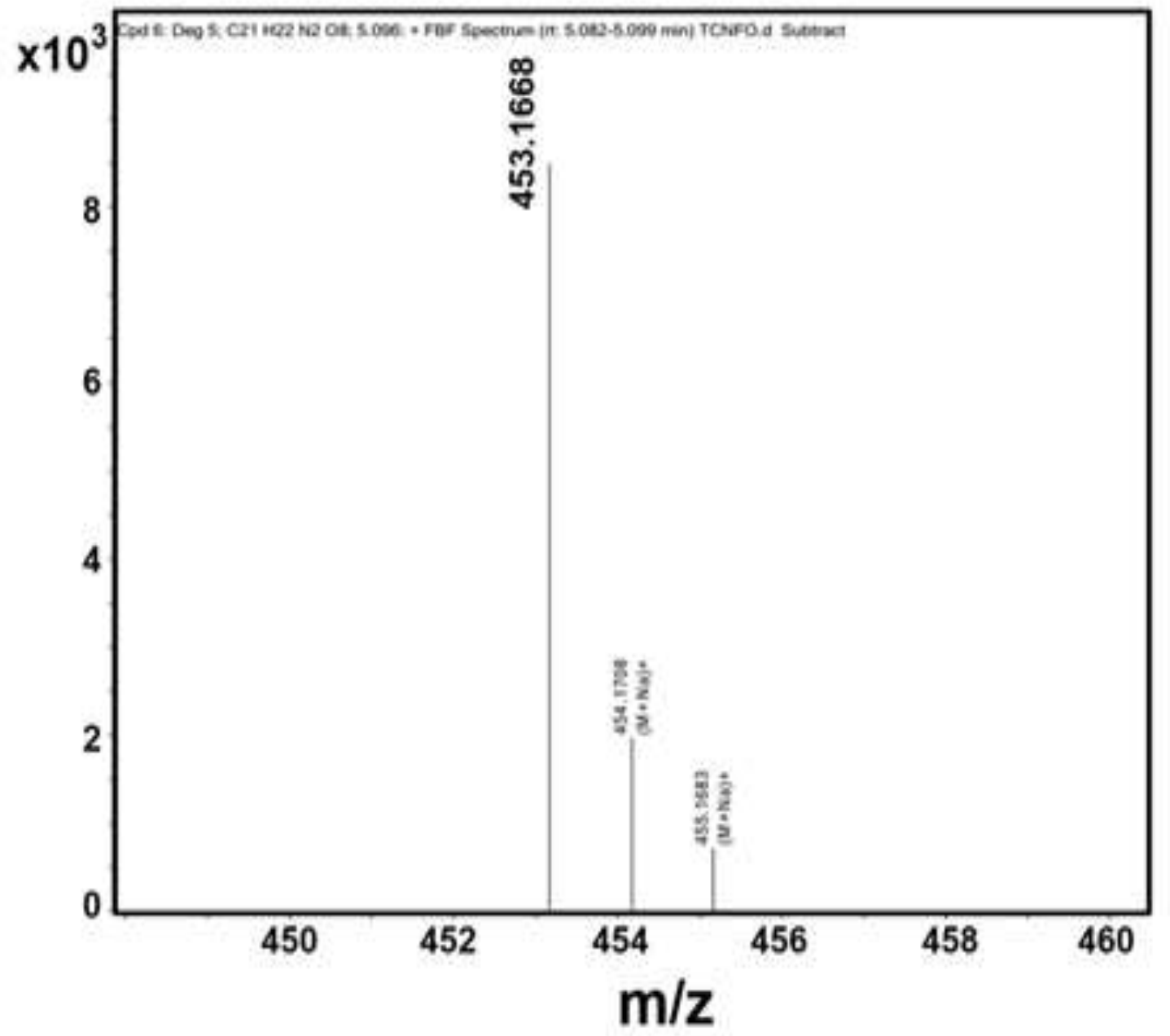

Figure S11(b) 


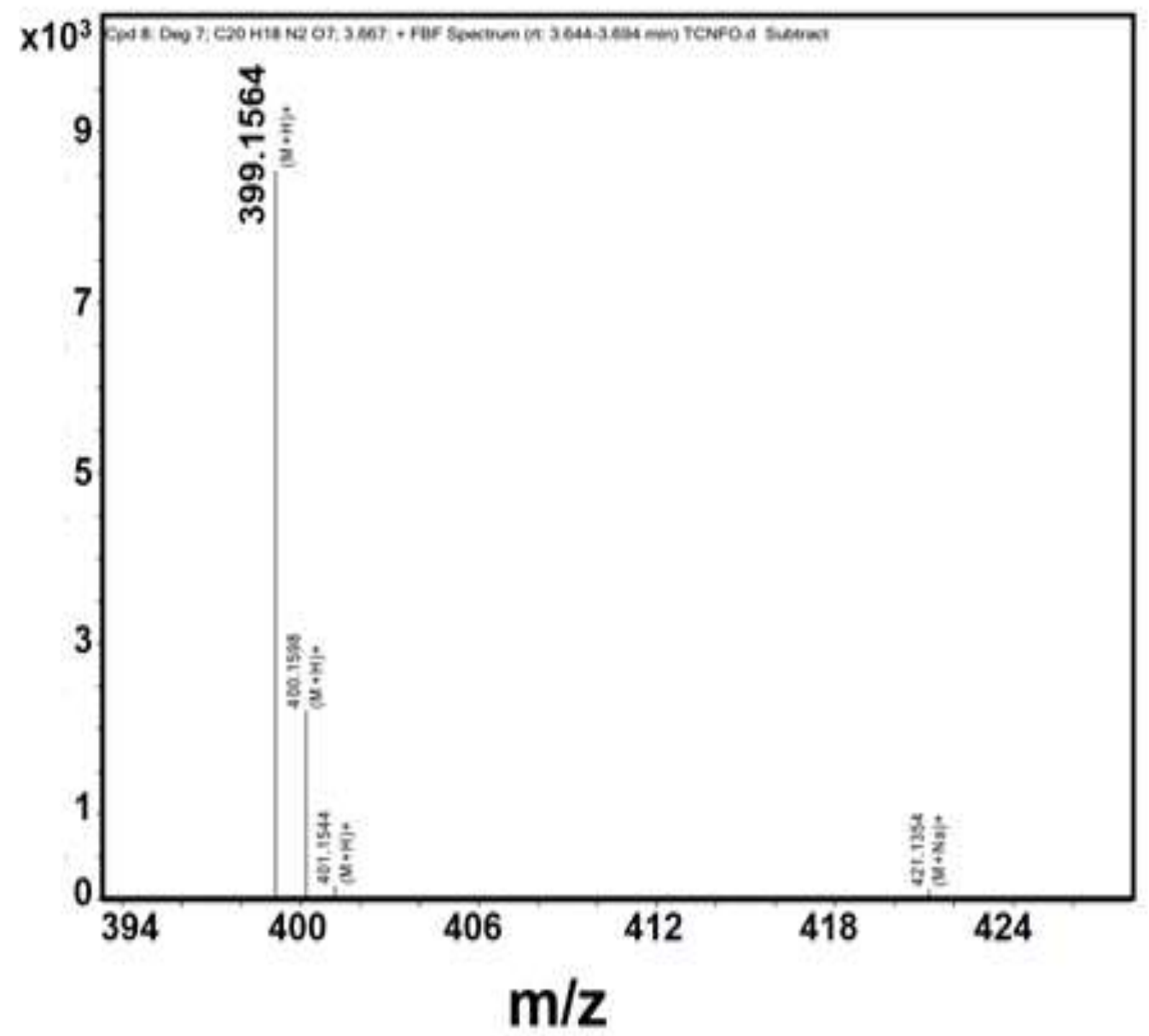

Figure S11 (c) 


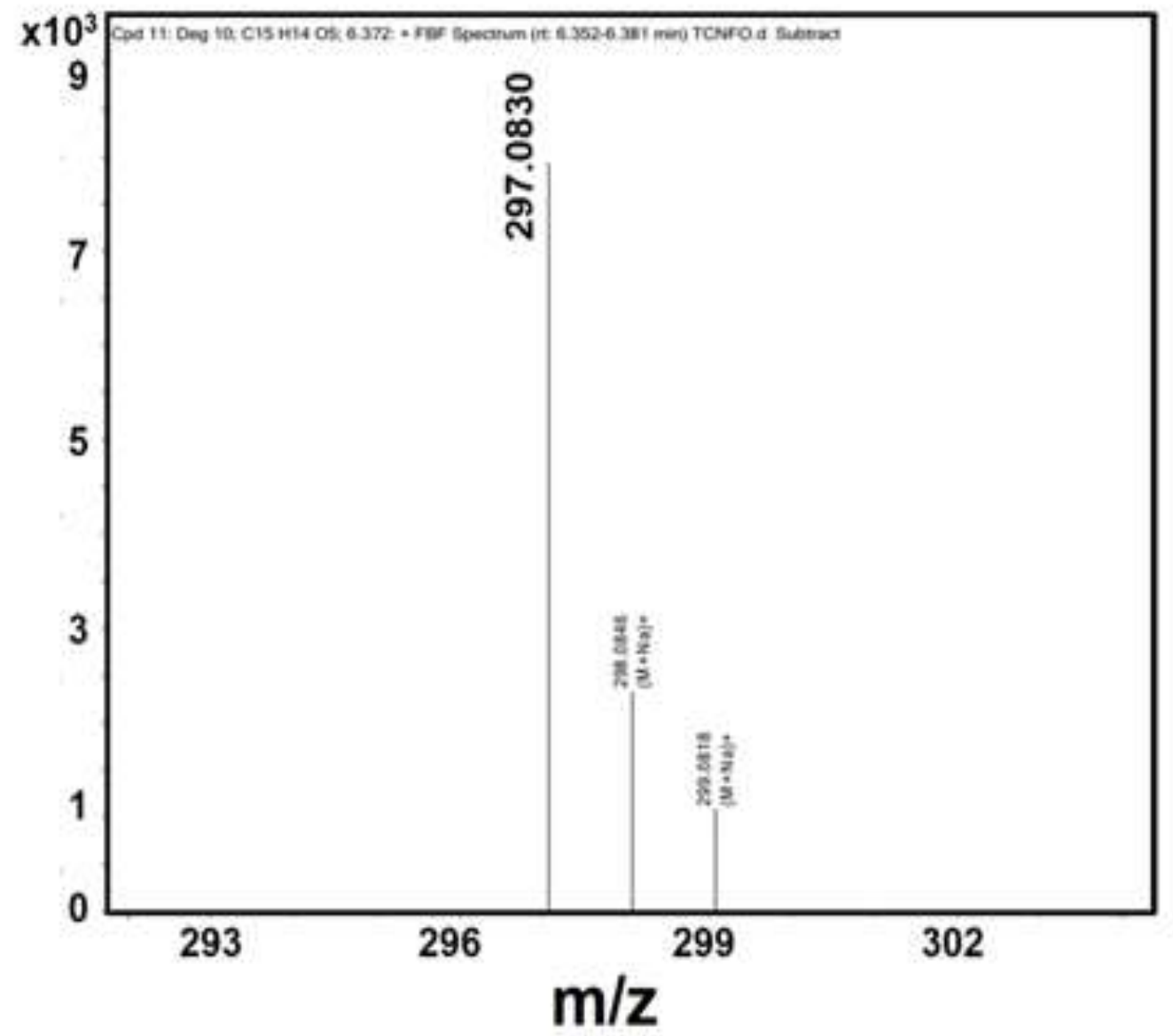

Figure S11 (d) 


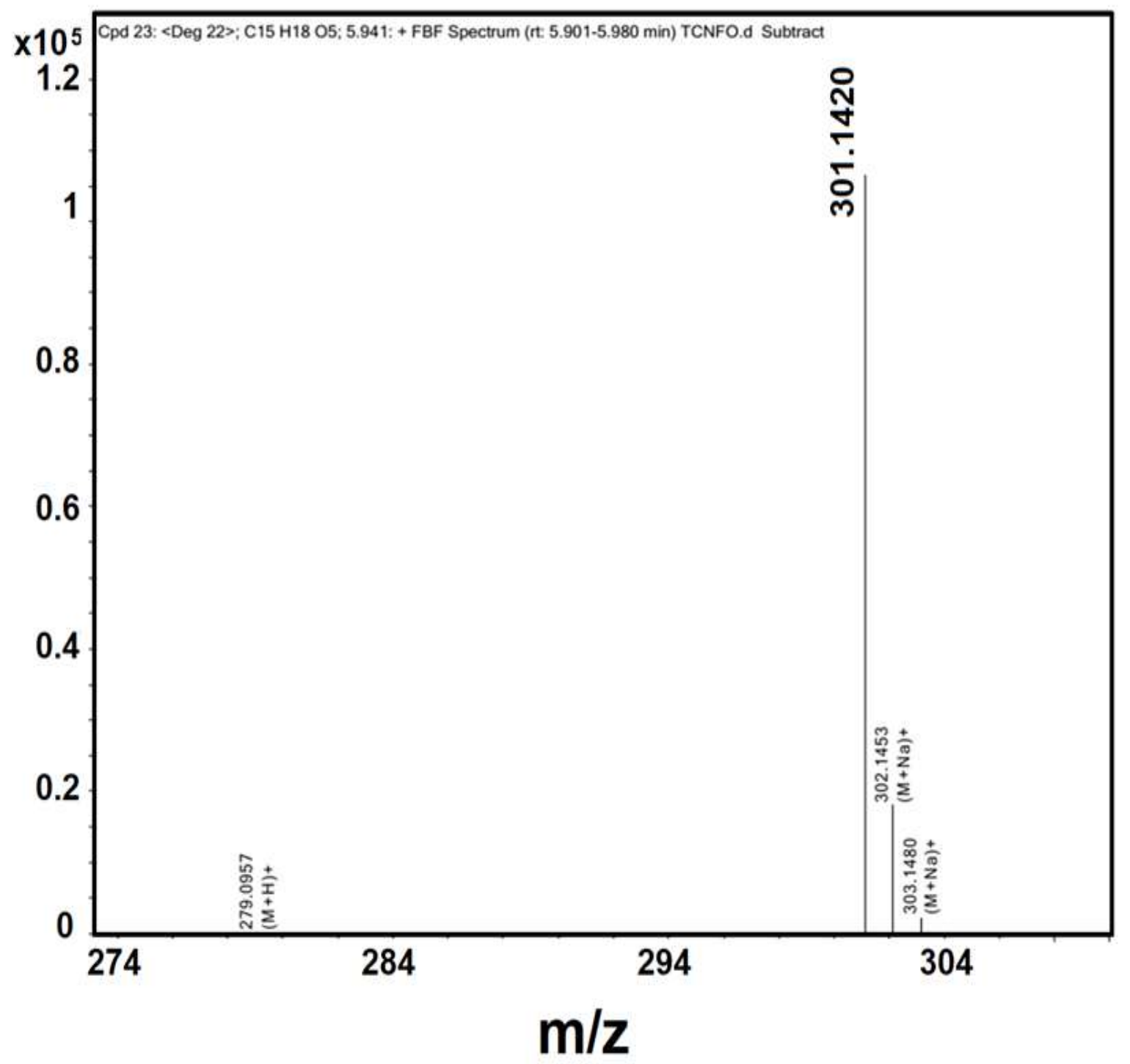

Figure S11(e) 


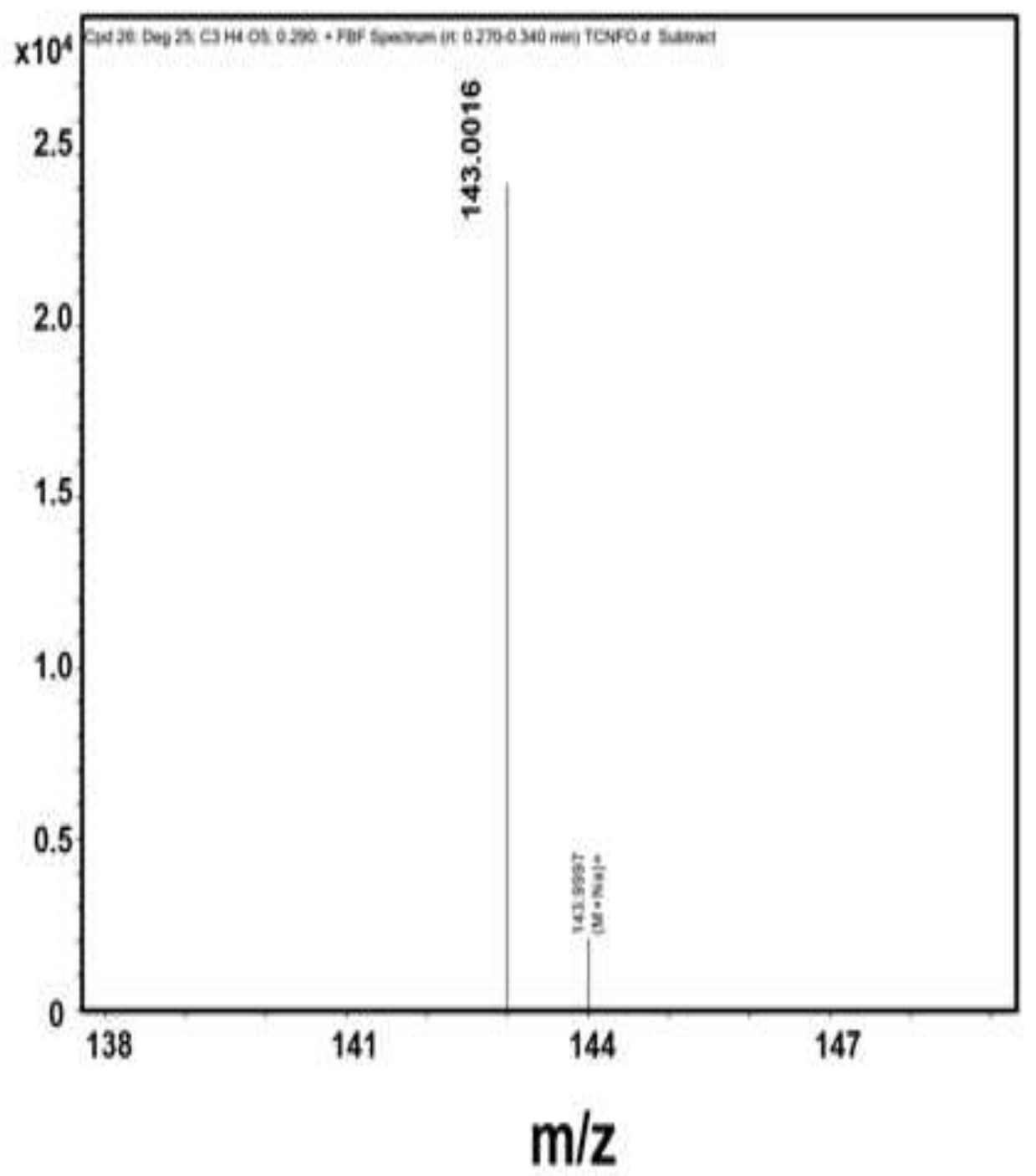

Figure S11(f) 


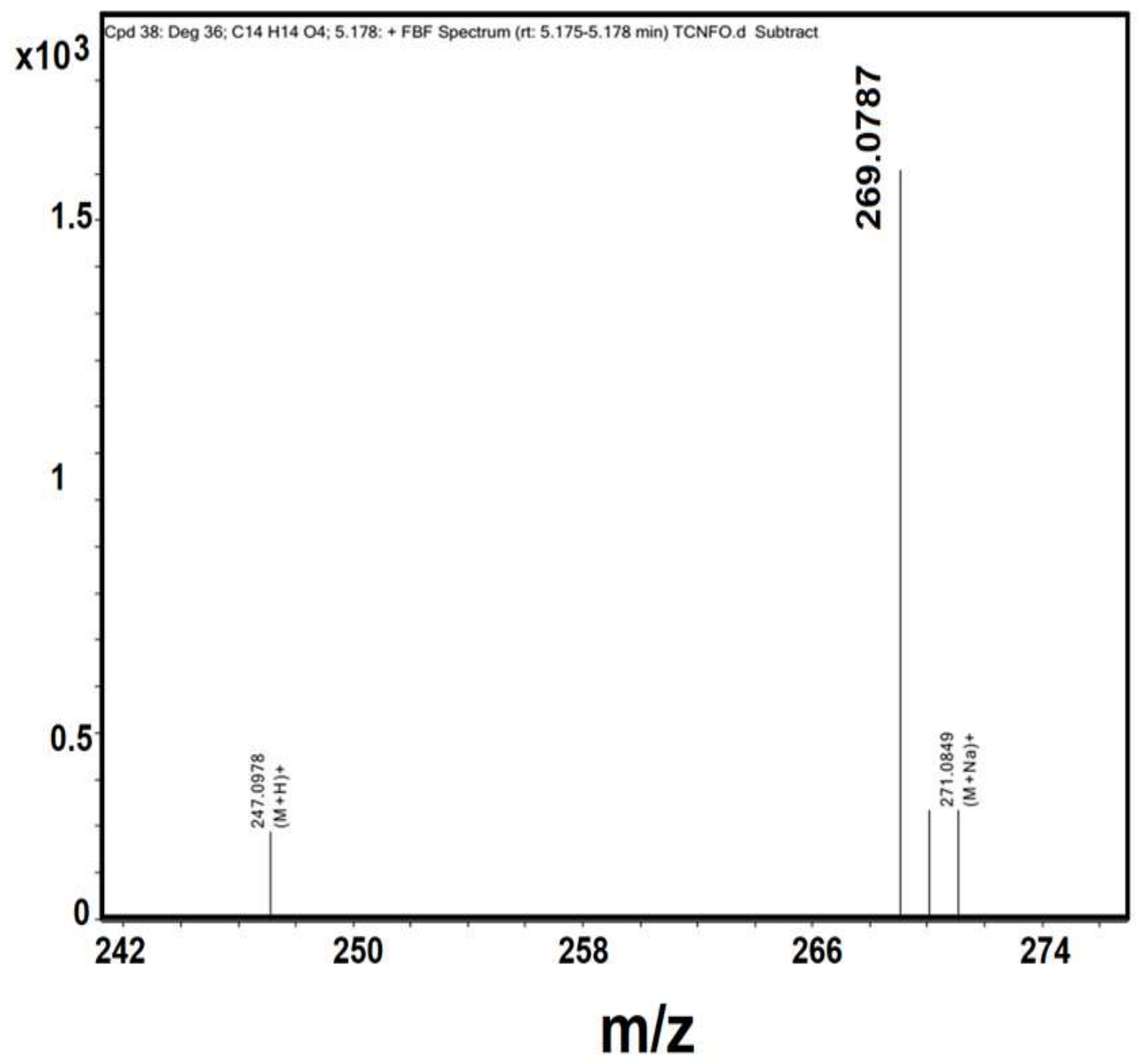

Figure S11(g) 


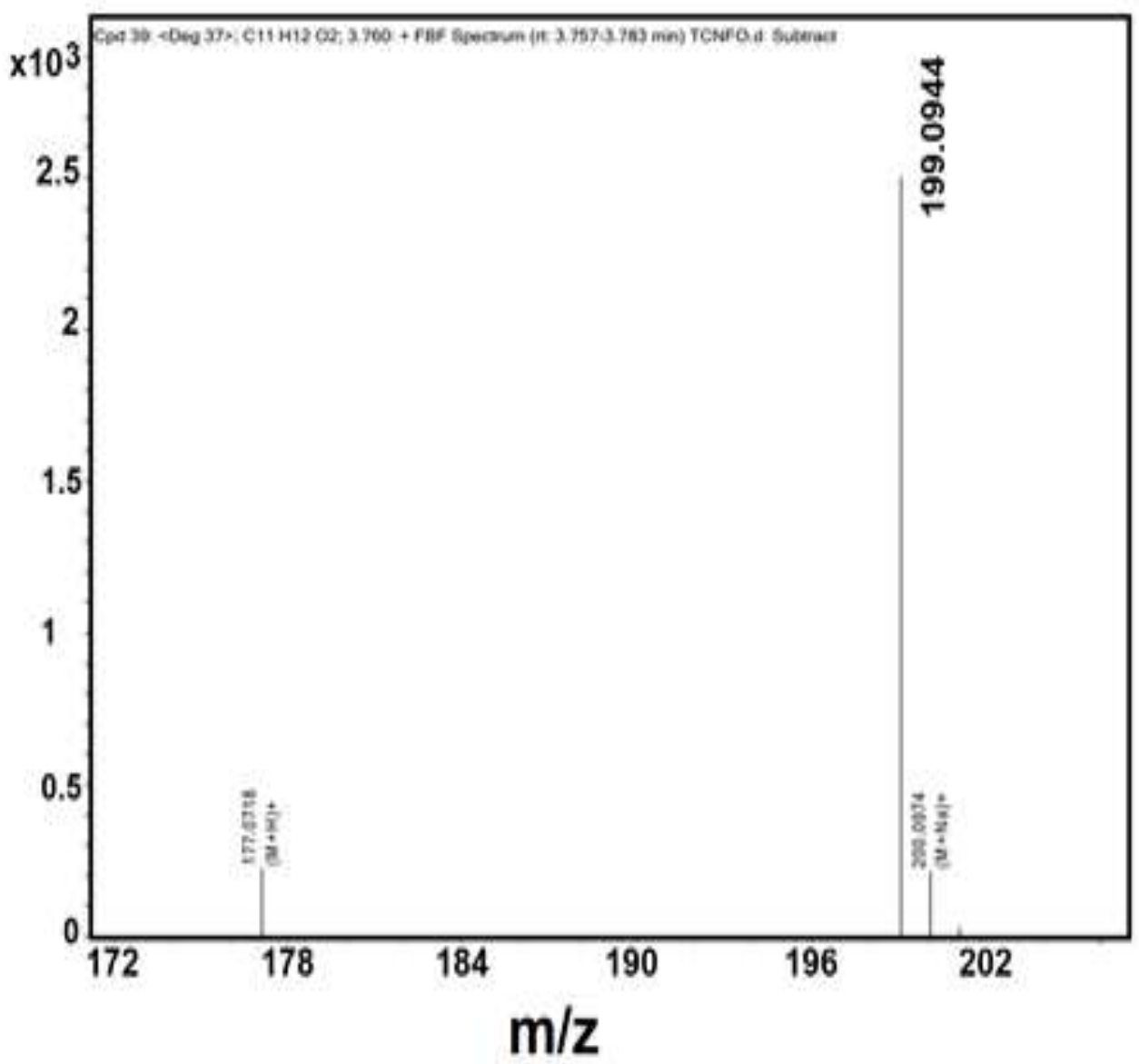

Figure S11(h)

Figure S11. The mass spectra for the intermediates are shown for (a-h) at various time intervals during the degradation of the TCH antibiotic using the SNFO catalyst. 


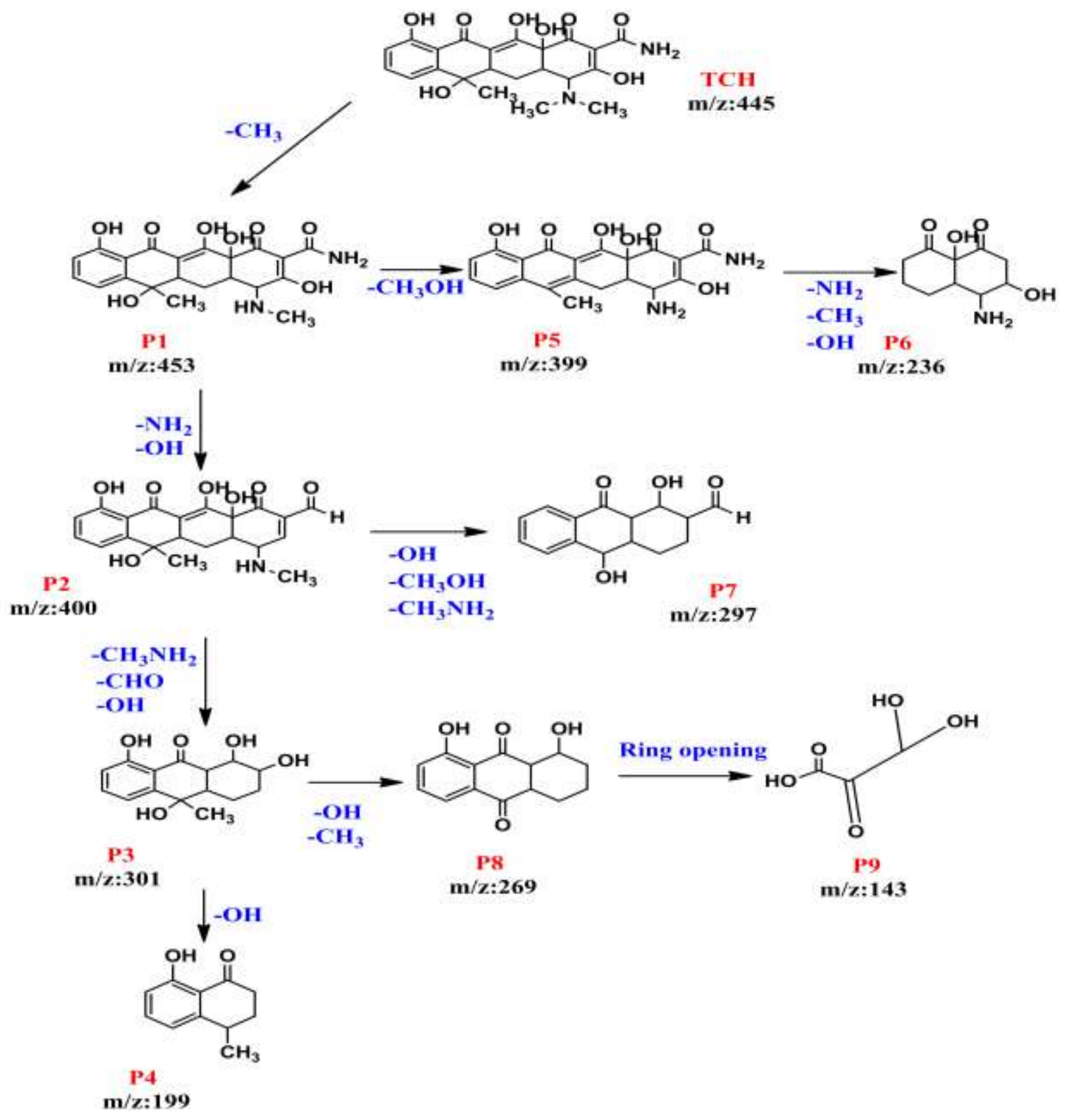

Figure S12. The proposed reaction pathways for the catalytic degradation of the $\mathrm{TCH}$ antibiotic molecule using the SNFO catalyst. 


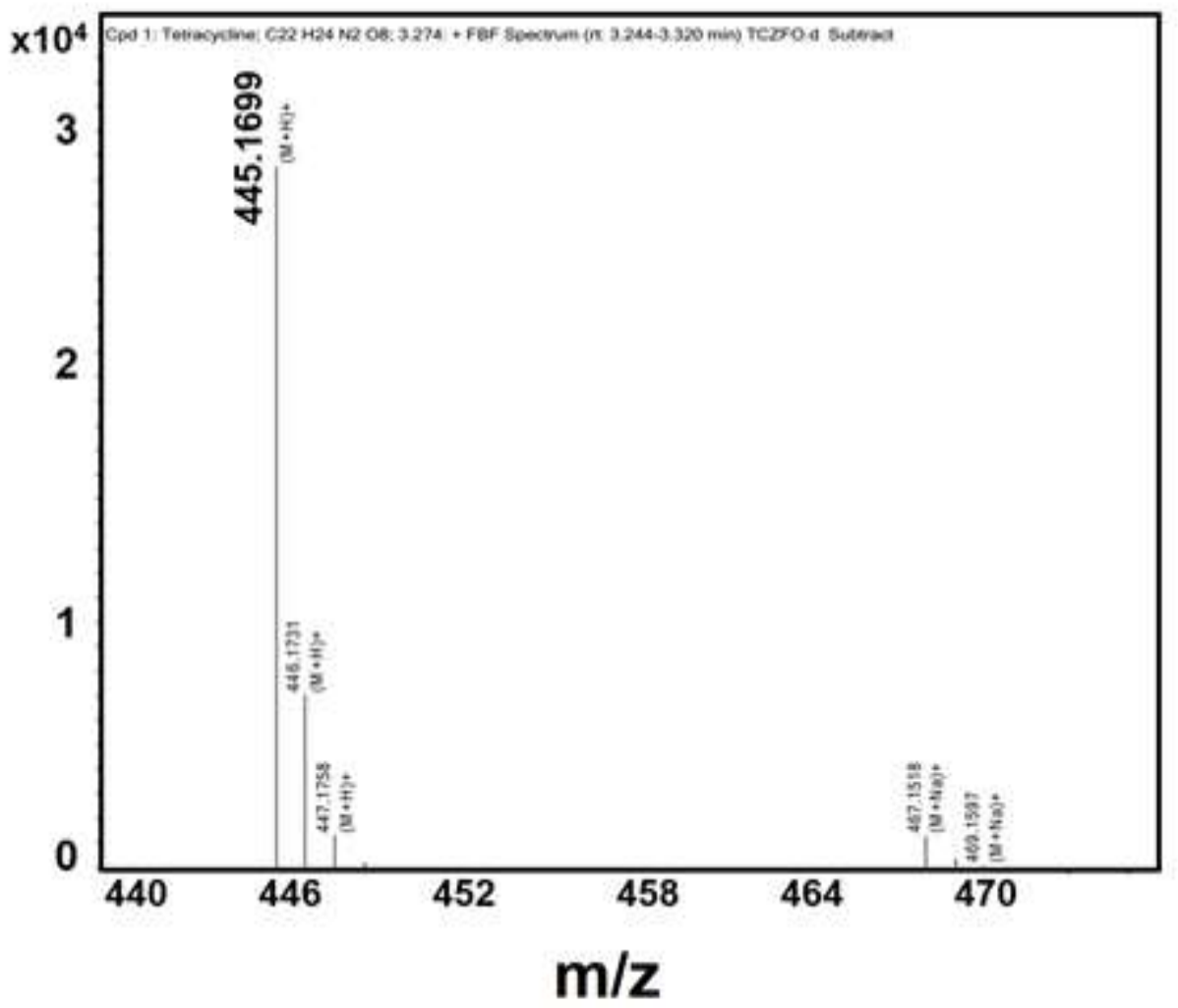

Figure S13(a) 


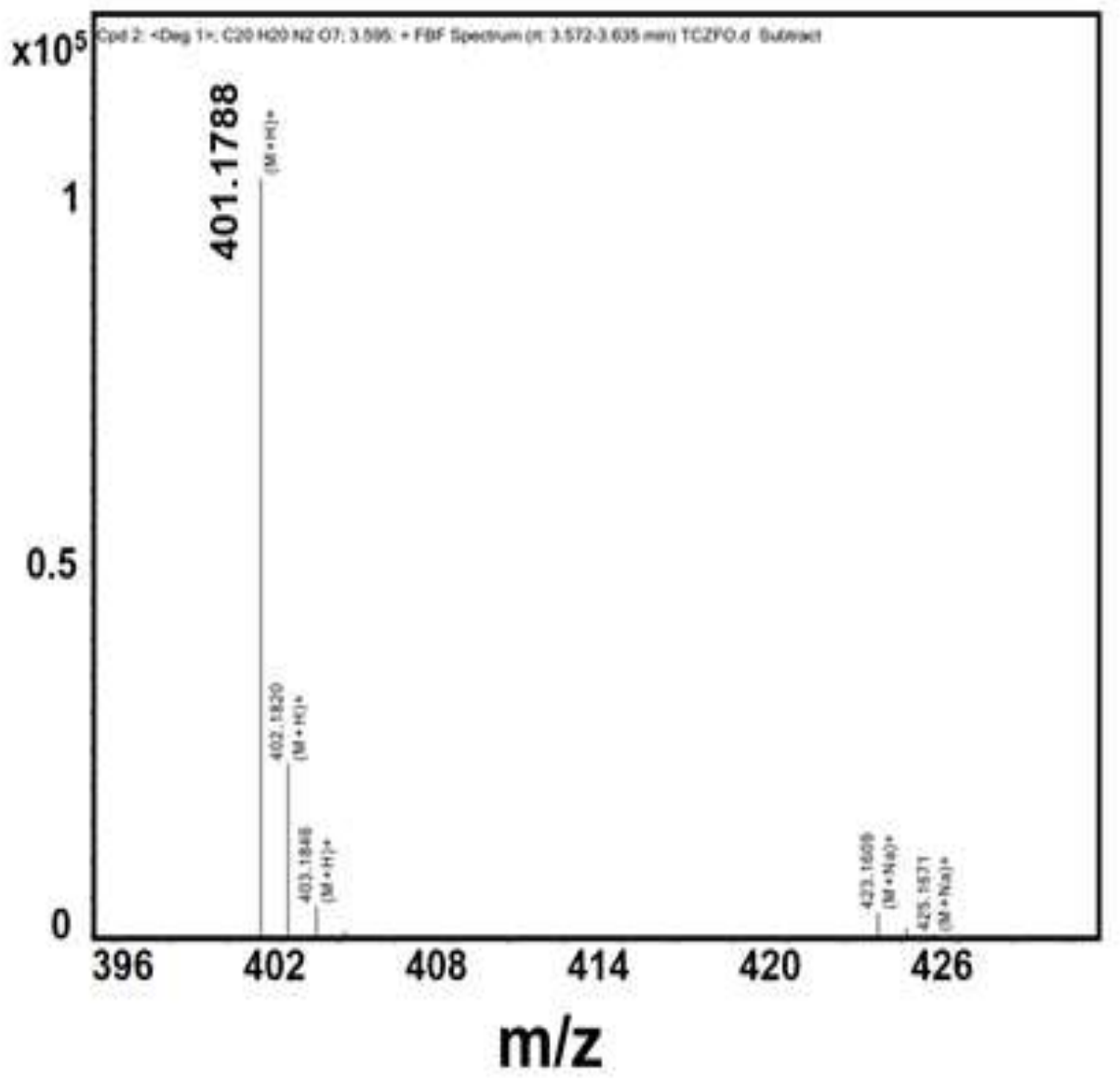

Figure S13(b) 


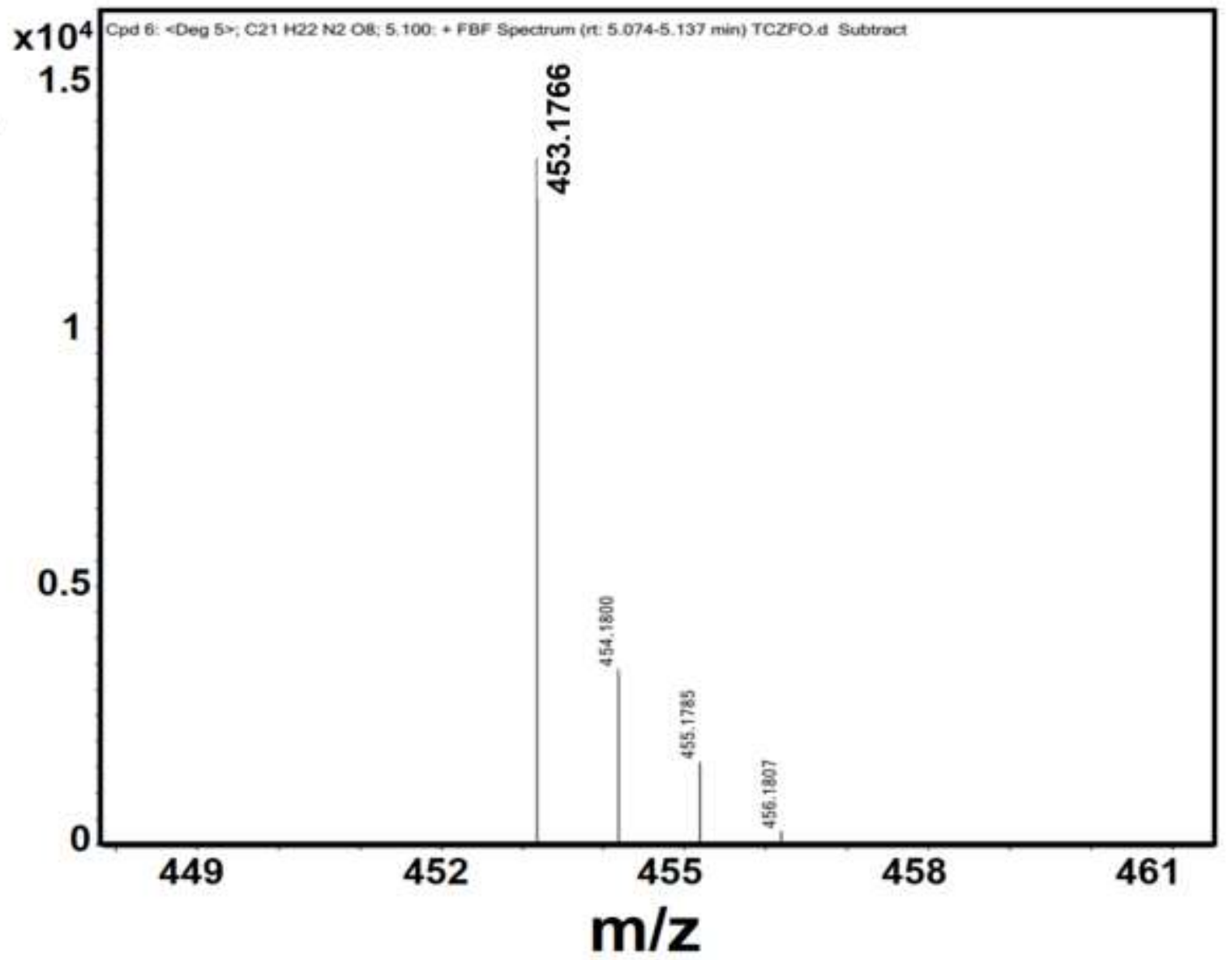

Figure S13(c) 


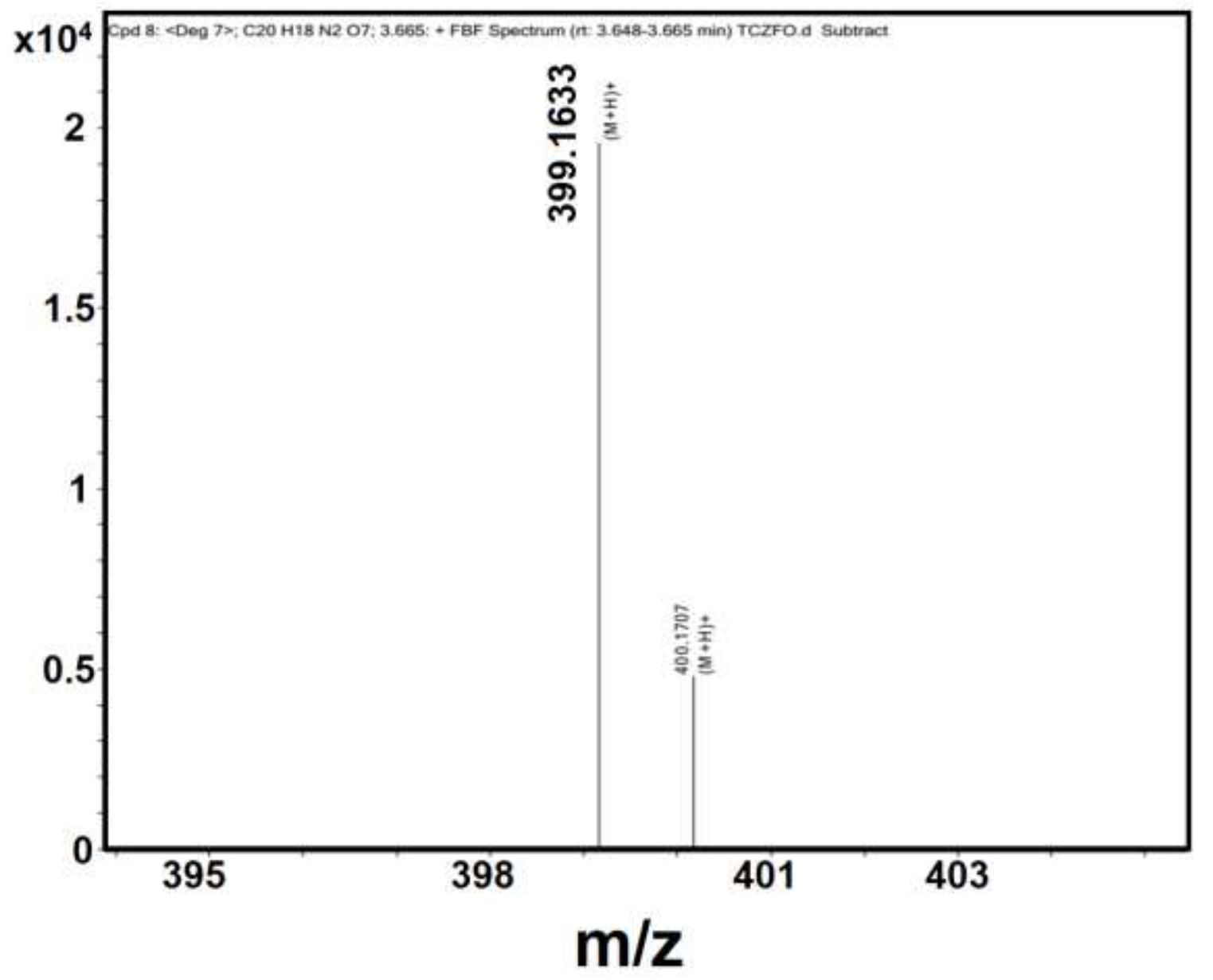

Figure S13(d) 


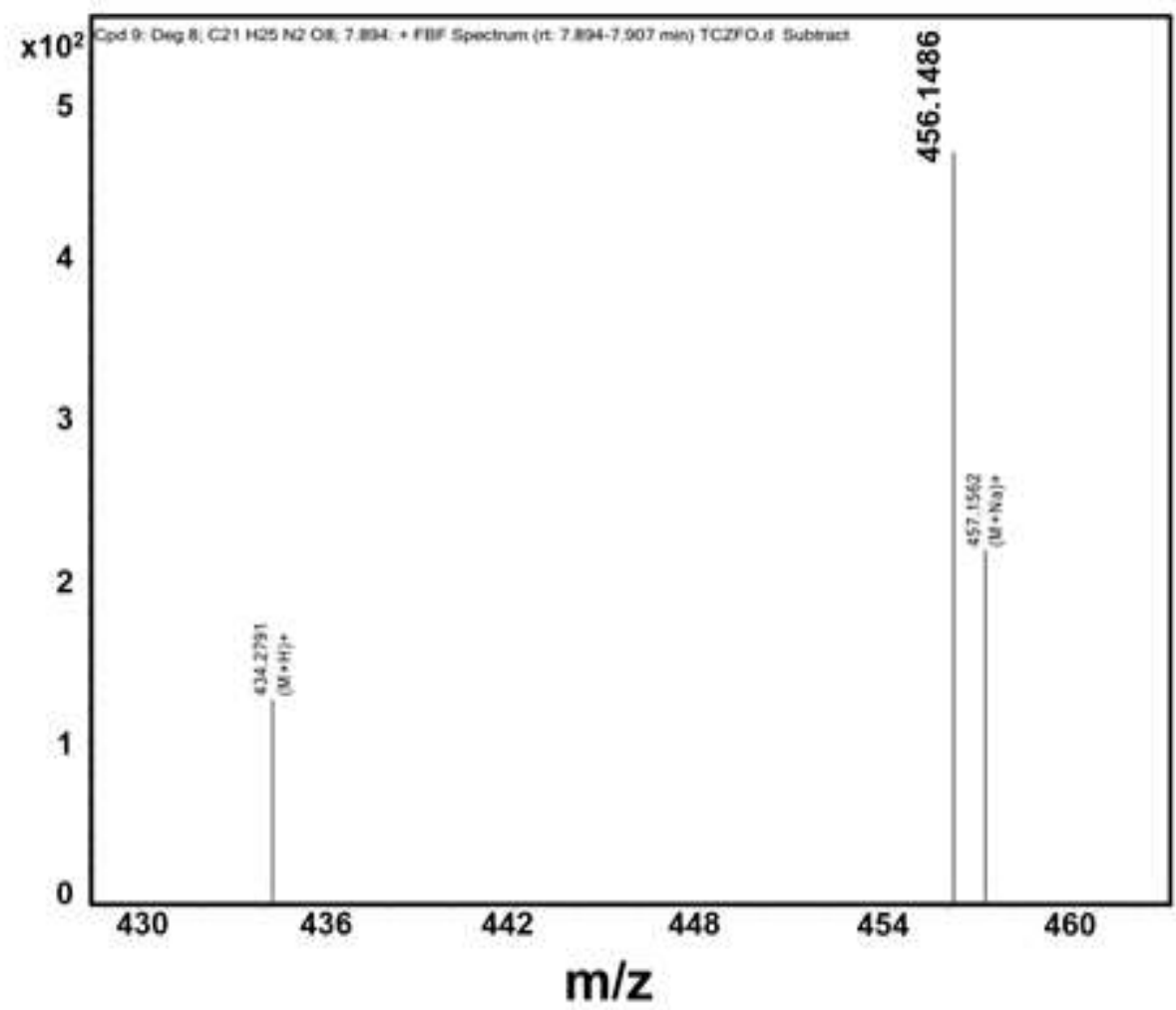

Figure S13(e) 


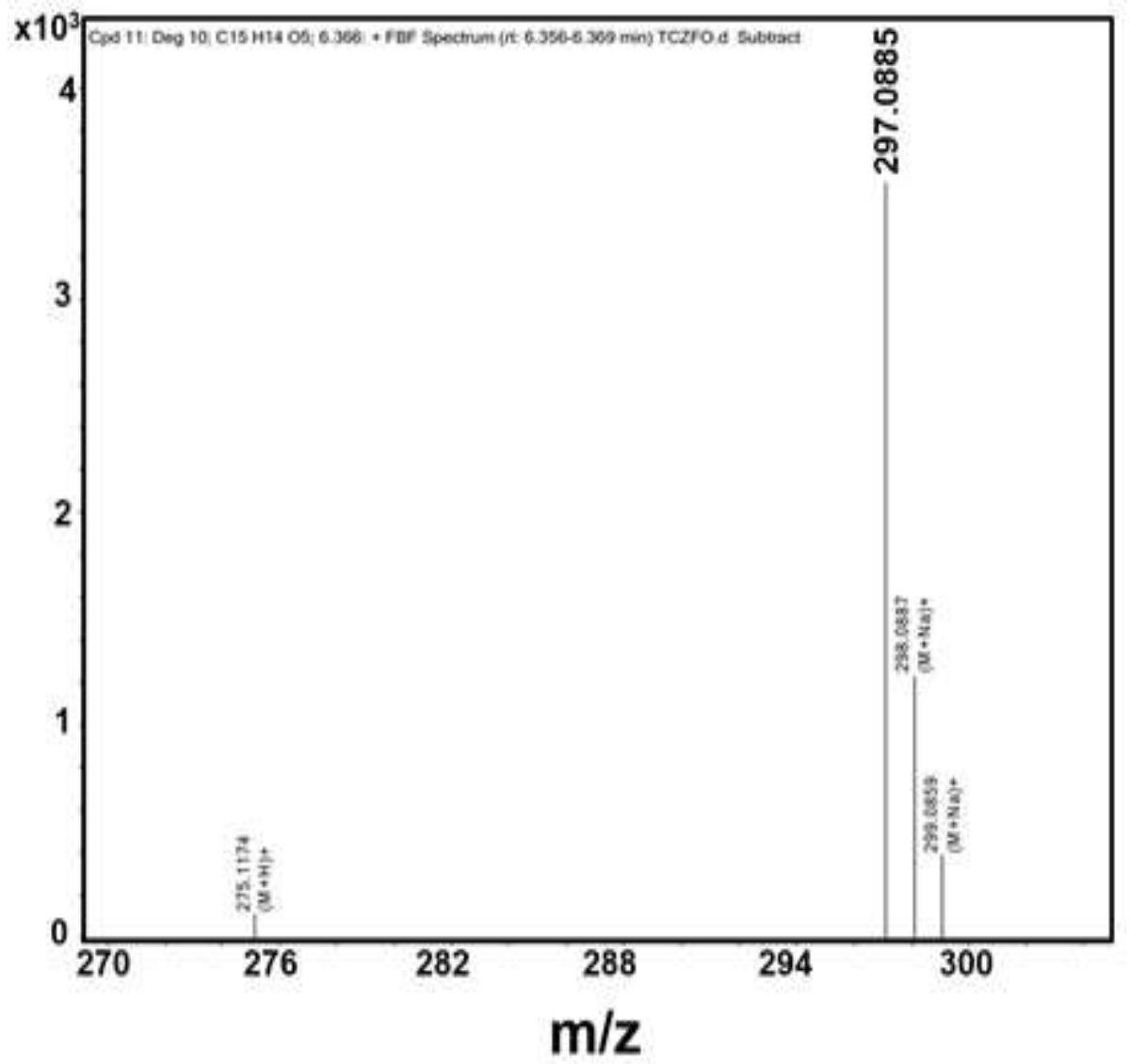

Figure S13(f) 


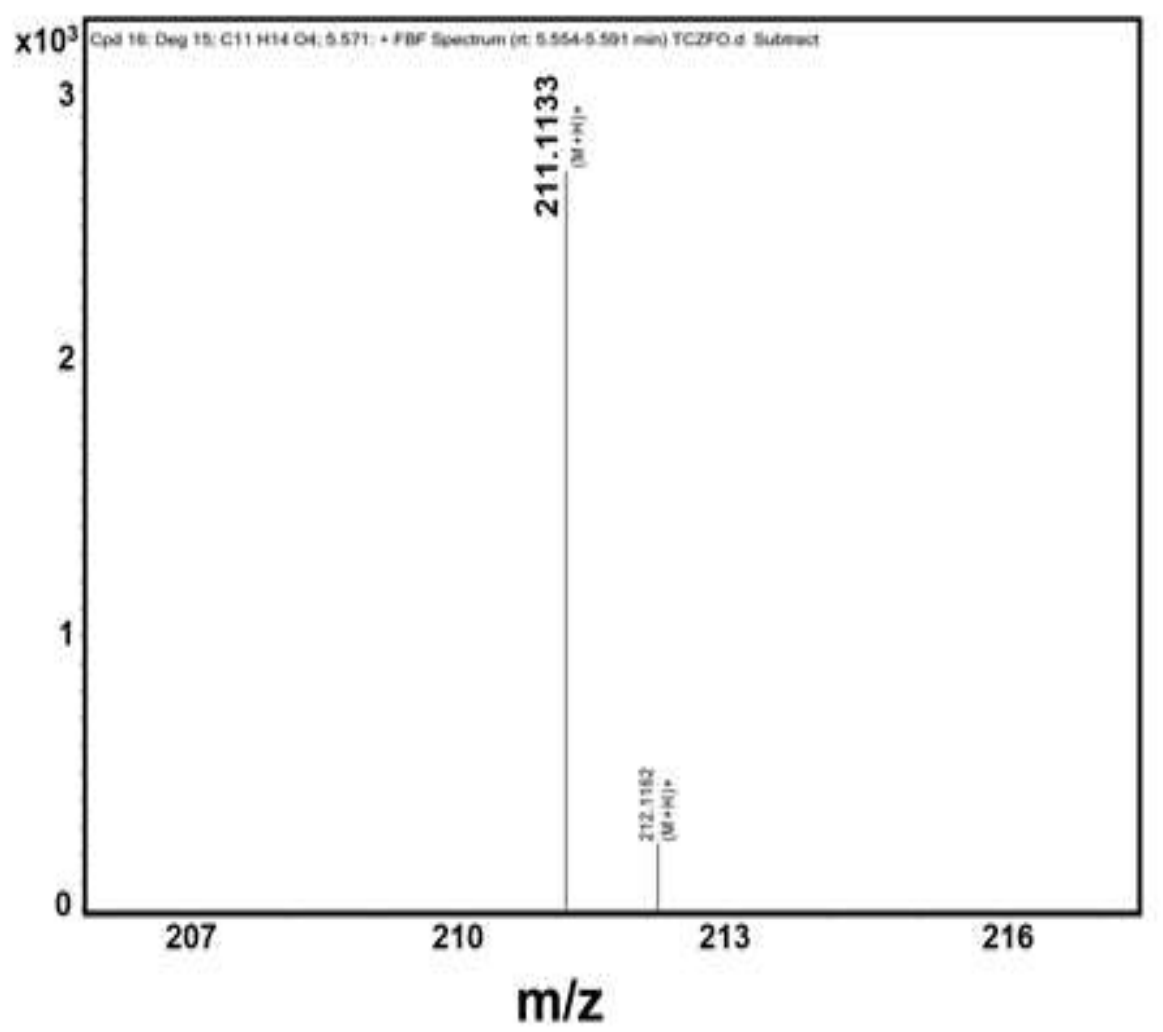

Figure S13(g) 


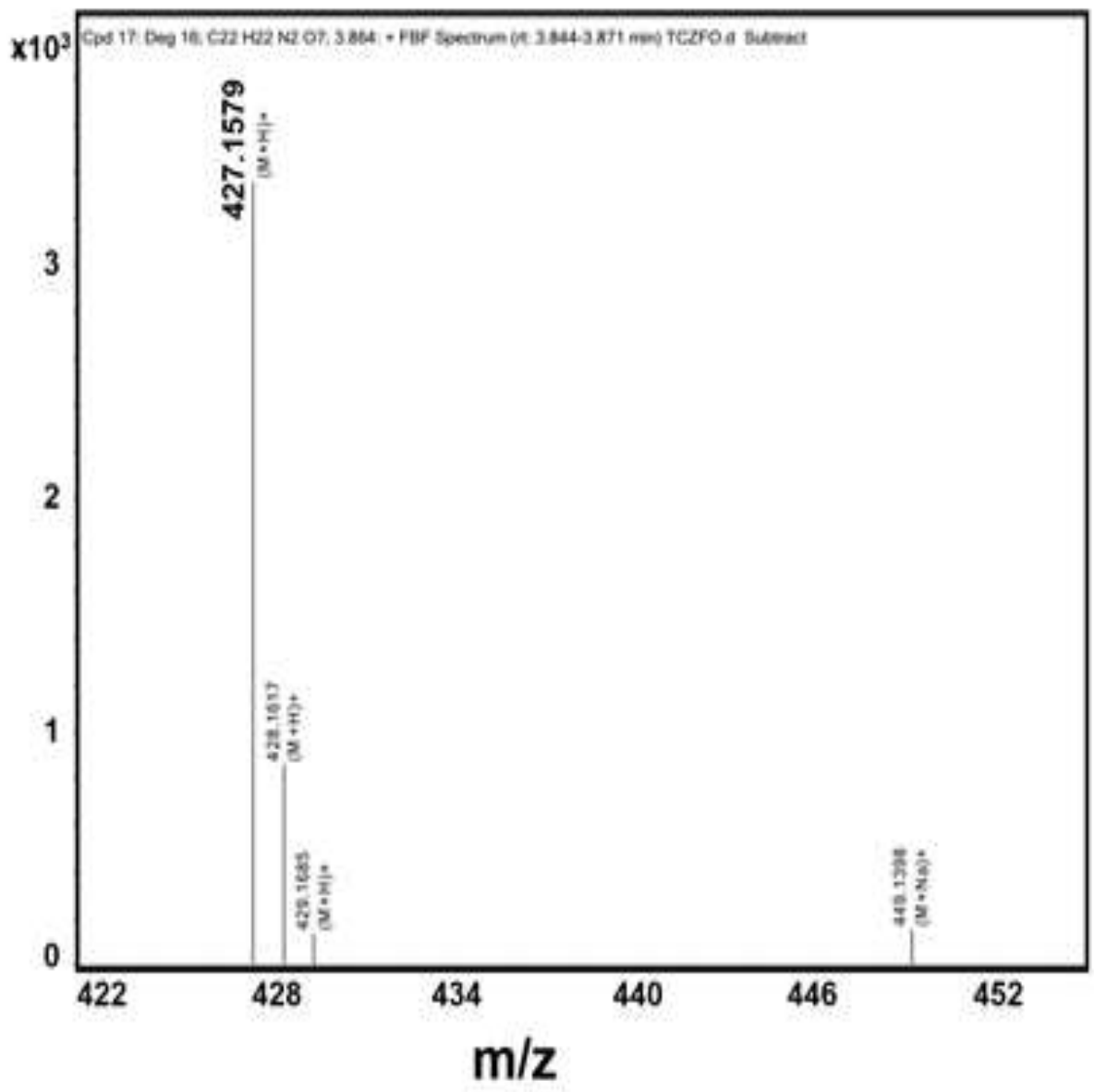

Figure S13 (h) 


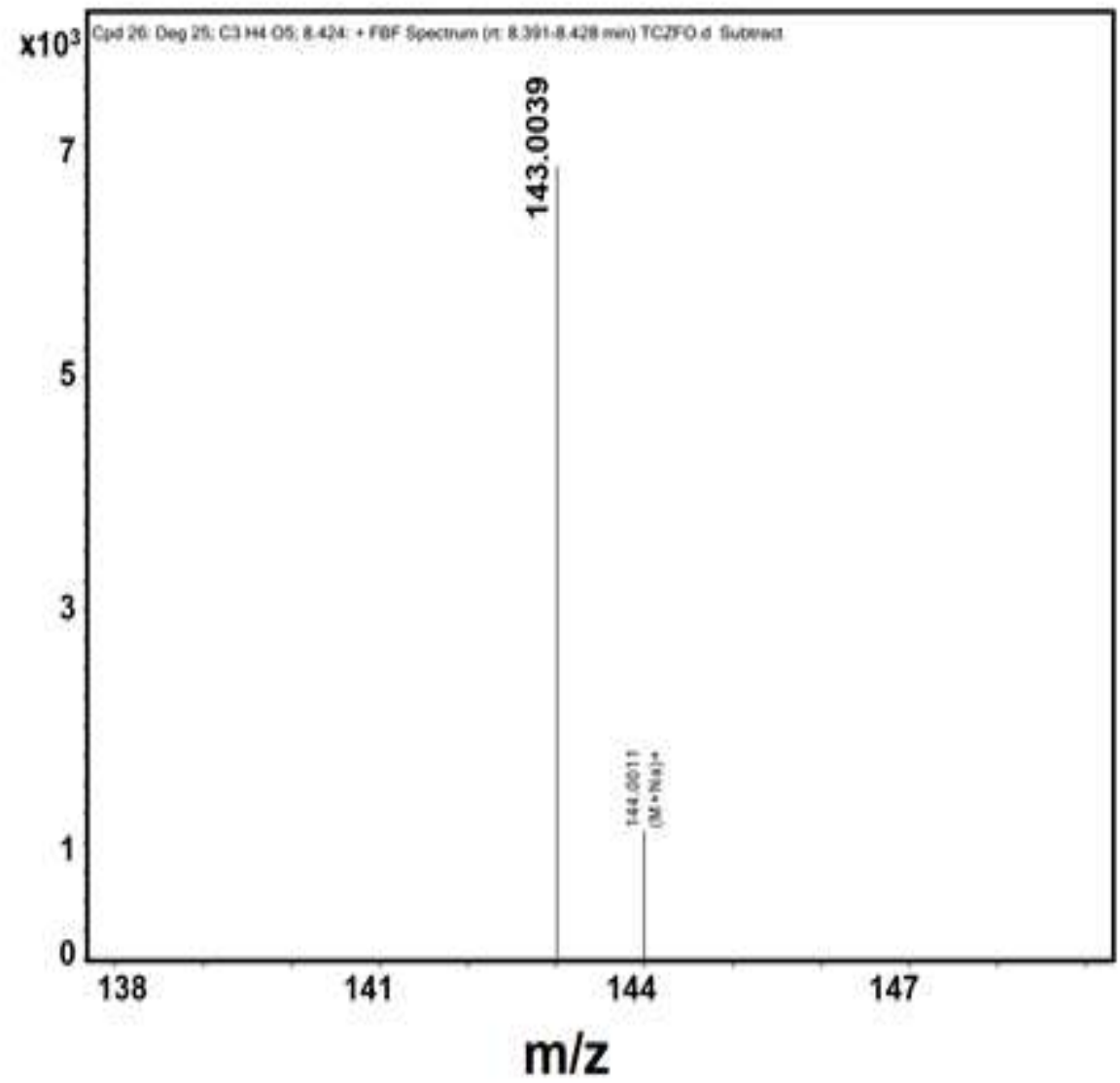

Figure S13(i) 


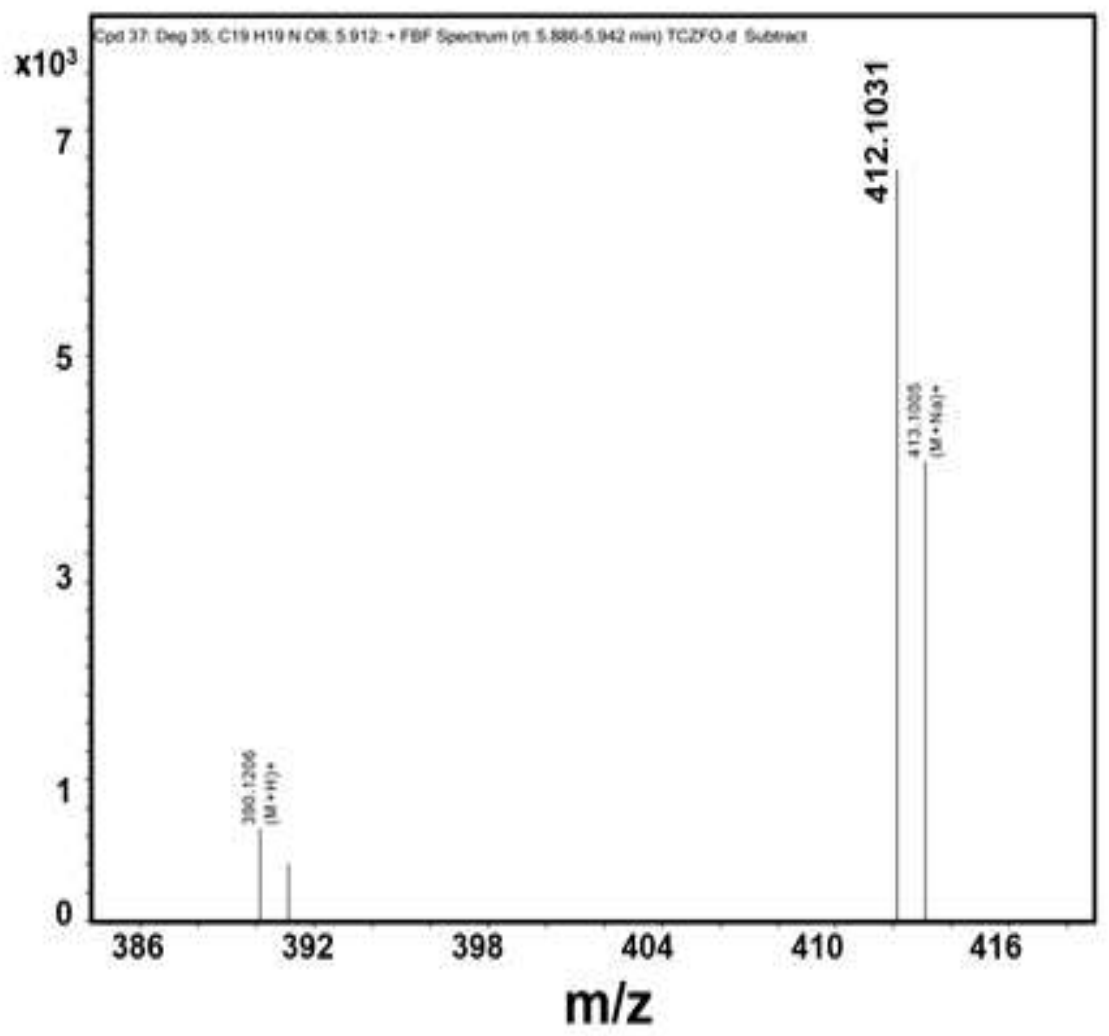

Figure S13(j) 


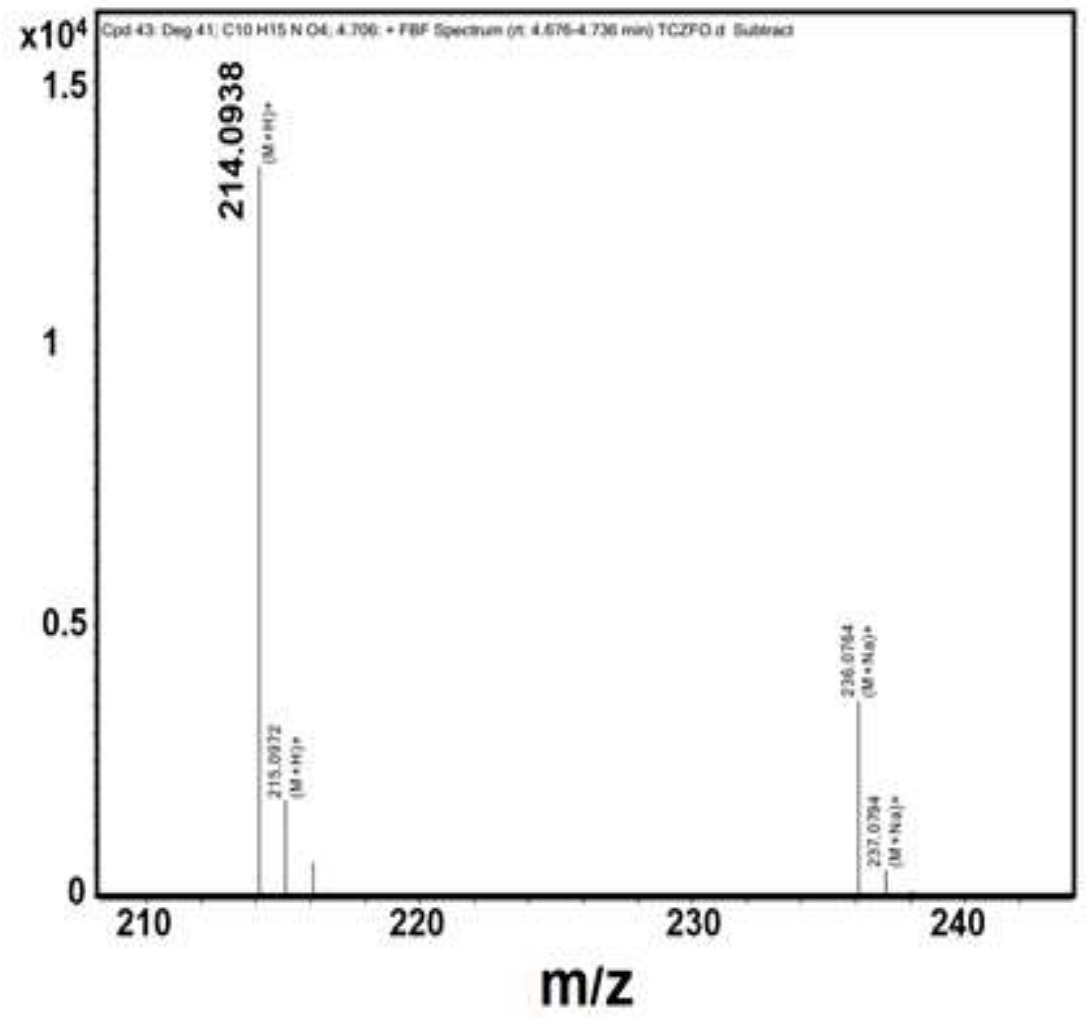

Figure S13 (k) 


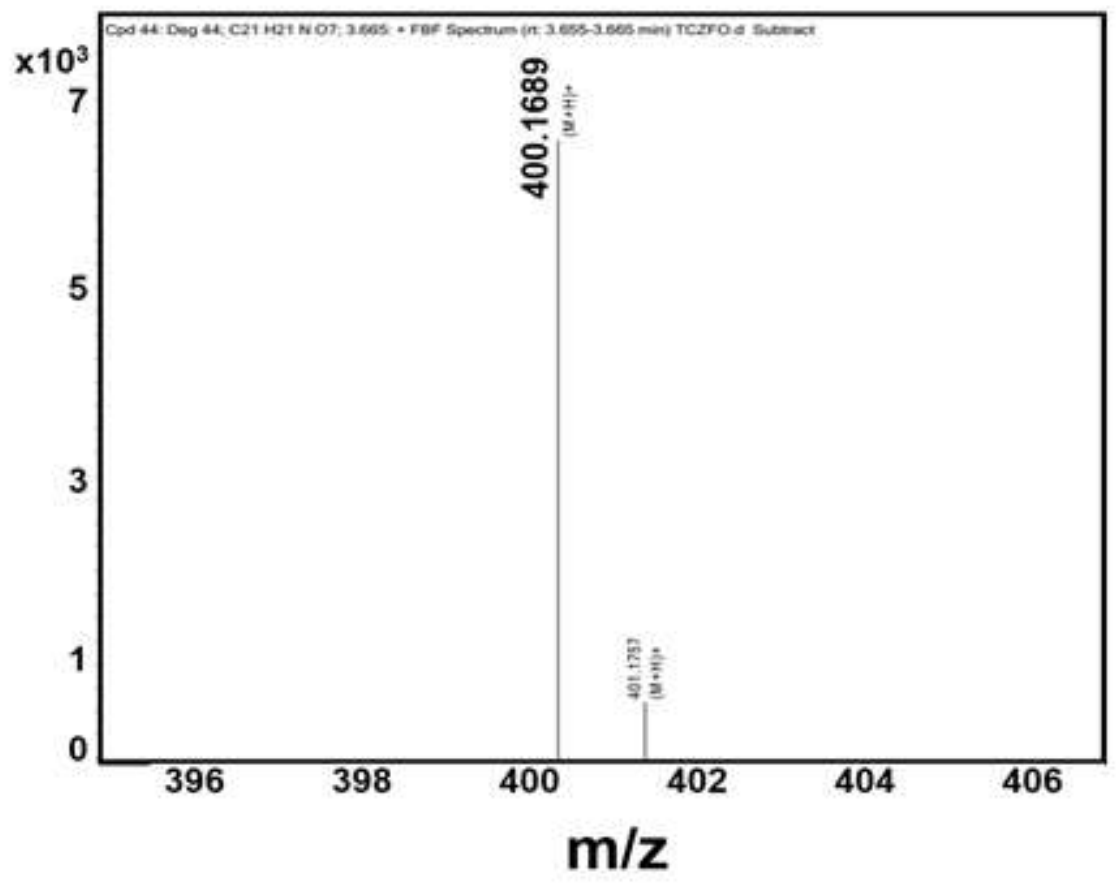

Fig. S13 (I)

Figure S13. The mass spectra for the intermediates are shown for (a-l) at various time intervals during the degradation of the TCH antibiotic using the SZFO catalyst. 


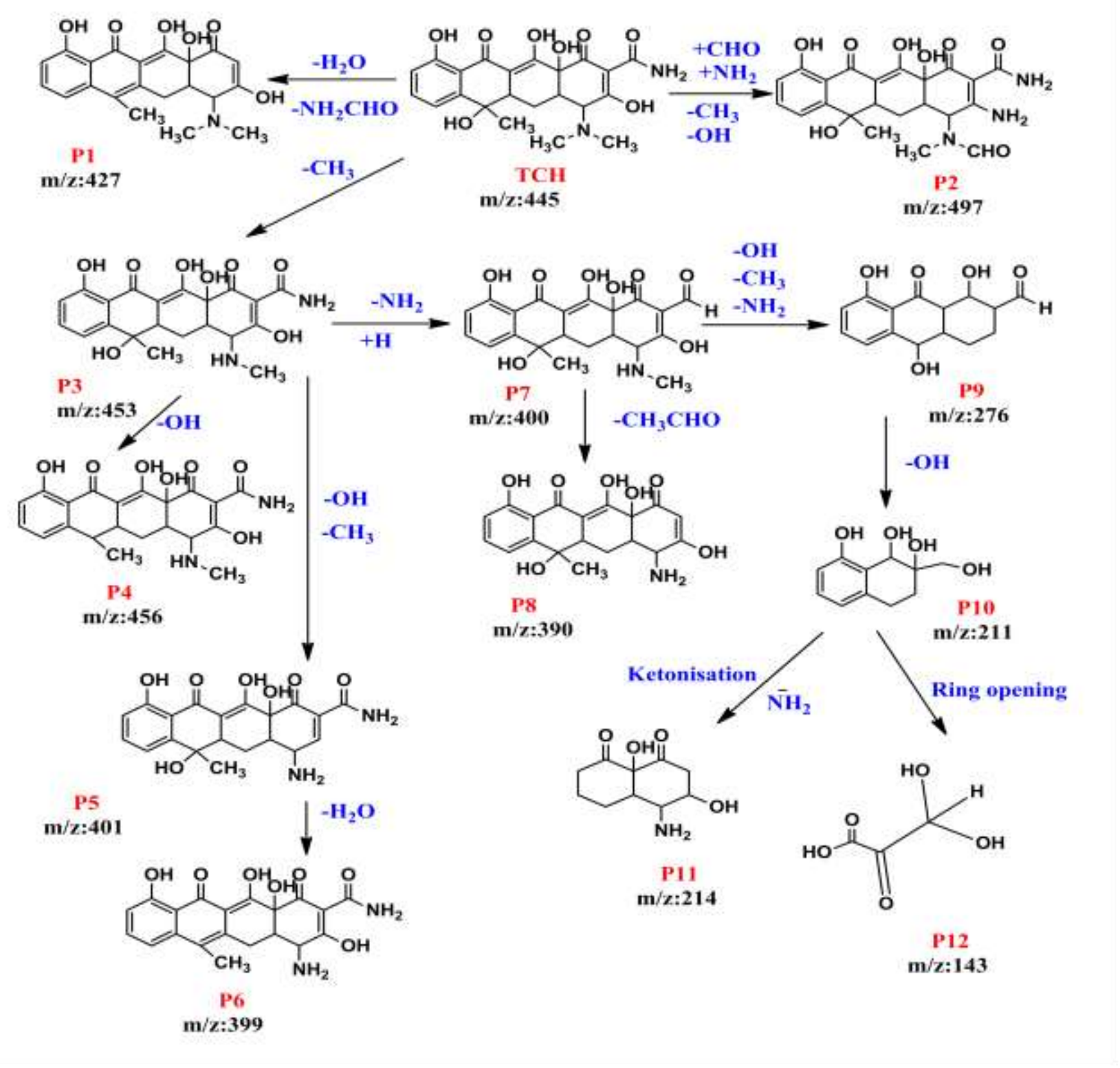

Figure S14. The proposed reaction pathways for the catalytic degradation of the TCH antibiotic molecule using the SZFO catalyst. 